\title{
Pre-service Mathematics Teachers' Mathematical Connections in the Context of Problem-Solving About the Derivative
}

\author{
Camilo Andrés Rodríguez-Nieto ${ }^{a}$, Flor Monserrat Rodríguez-Vásquez ${ }^{\mathrm{b}}$ and Javier García-García ${ }^{\mathrm{c}}$ \\ a Autonomous University of Guerrero (UAGro), Mexico (ORCID: 0000-0001-9922-4079) \\ ${ }^{\mathbf{b}}$ Autonomous University of Guerrero (UAGro), Mexico (ORCID: 0000-0002-9596-4253) \\ ${ }^{\mathbf{c}}$ Autonomous University of Guerrero (UAGro), Mexico (ORCID: 0000-0003-4487-5303)
}

Article History: Received: 19 September 2020; Accepted: 4 February 2021; Published online: 5 February 2021

\begin{abstract}
The mathematical connections made by five Pre-Service Mathematics Teachers (PSMTs) when solving problems on the derivative were analyzed. The conceptual framework used was the typology of intra-mathematical connections. For data collection, semi-structured interviews were conducted, and a questionnaire was designed, which included three tasks about of the derivative, which were analyzed through the thematic analysis method. The results showed that PSMTs made mathematical connections: meaning, different representations, procedural, part-whole, implication and feature. We identified that the PSMTs' difficulties in establishing connections are caused by the meaning they have on the derivative concept, acquired in their received teaching and, if they are not attended, they can be reproduced in their future practice as in-service teachers.
\end{abstract}

Keywords: Mathematical connections, pre-service mathematics teachers, problem-solving, derivative

DOI: $10.16949 /$ turkbilmat.797182

\section{Introduction}

The mathematical connections are an important topic in the teaching and learning of mathematics. Since, when a student makes mathematical connections between concepts, representations, meanings and between mathematics and real life, he could better understand a mathematical concept (Evitts, 2004; García-García \& Dolores-Flores, 2019, 2020; National Council of Teachers of Mathematics [NCTM], 2000; Özgen, 2013). Furthermore, Pambudi, Budayasa and Lukito (2018) affirmed that "mathematical connections have a close relationship with "problem-solving", in which the ability of students to connect mathematical ideas will determine the success of students in solving mathematical problems" (p. 74). This allows us to ensure that it is important to link the mathematical problem-solving with mathematical connections, in fact, the connections arise when students or teachers solve tasks and can be identified in the worksheets, in oral or mimic arguments (García-García \& Dolores-Flores, 2018), and appear in the curriculum.

In the curriculum of different countries, mathematical connections play a relevant role, for example, they are considered a basic competence for students to solve problems, establish relationships between mathematical ideas, between previous knowledge and new knowledge as evidenced in Catalonia (Departament d'Ensenyament, 2017), in Colombia (Ministry of National Education [MEN], 2006), in Singapore (Ministry of Education [MOE], 2006), in South African (Mwakapenda, 2008), in United States of American (NCTM, 2000); in Turkey (Özgen, 2013), in Brazil (São Paulo State, 2012). Particularly in the Mexican curriculum, the DGB (General Directorate of High-School (DGB for its acronym in Spanish)) (2018) proposes that in the development of the content of the derivative, derivation formulas, theorems, maximum and minimum criteria should be applied in the solution of real situations or daily life, implicitly evidencing the connections intra-mathematical and extra-mathematical. Likewise, the Curriculum of Mathematics of higher-level of the Autonomous University of Guerrero [UAGro] (2009) suggests that different meanings and interpretations of the derivative be promoted (velocity, tangent, rate of change and the formal definition of the derivative), as well as solving application problems, hinting that mathematical connections should be promoted.

Just as mathematical connections in the curriculum are important, they are also of interest in the field of research in Mathematical Education, for example, Rodríguez-Nieto (2020) shows the role of internal, external and meaning connections in measurement systems in daily practices from an ethnomathematical point of view. From the elementary school grades, it is considered essential that students make mathematical connections. In this regard, Kenedi, Helsa, Ariani, Zainil and Hendri (2019) affirmed that:

The ability of students to connect mathematically is one of the essential things that must be achieved by students in the learning process because if students know the relationship between the concepts, they will quickly understand the mathematics itself and open opportunities for students to develop their mathematical skills (p. 70). 
Other research has focused on the study of mathematical connections at the pre-university and university levels. Dolores-Flores and García-García (2019) explored the mathematical connections that pre-university students established when they were proposed problems that involved the concept of rates of change. In relation to the concepts of Calculus, Dolores-Flores and García-García (2017) investigated the intra-mathematical and extra-mathematical connections that occurred when university students solve tasks that involved the definite integral; García-García \& Dolores-Flores $(2018,2019,2020)$ emphasized the mathematical connections made by pre-university when solving tasks involving the concepts of derivative and integral and real-life situations. For his part, Yavuz-Mumcu (2018) studied the mathematical connections made by pre-service teachers on derivative. Likewise, Rodríguez-Nieto, Rodríguez-Vásquez and Font (2020) made a theoretical reflection on the mathematical connections made by a teacher of Differential Calculus when he taught the subject of the derivative. Furthermore, Rodríguez-Nieto, Font, Borji and Rodríguez-Vásquez (2021) analyzed mathematical connections from two theoretical perspectives (extended theory of mathematical connections and the ontosemiotic approach).

The main motivation to research on mathematical connections is because it has been identified in the literature review that students find it difficult to make connections, and therefore have drawbacks to understand mathematical concepts. Likewise, they focus on making algorithmic, mechanical processes using derivation rules (Antonio, Escudero \& Flores, 2019). In the case of studies about the derivative, Hashemi, Salleh Abu, Kashefi and Rahimi (2014) reported that students have little conceptual understanding of the derivative, due to the poor connection between algebraic and graphic aspects. Likewise, students have difficulty connecting and use multiple representations (graphic, symbolic, etc.) of the derivative (Kula-Ünver, 2020; Pino-Fan, Godino \& Font, 2015; Sánchez-Matamoros, Fernández \& Llinares, 2015; Sari, Hadiyan \& Antari, 2018). Also, in another study on understanding the derivative some students stayed at the inter-level since it is difficult for them to relate the function $f$ with its derivative and they graph the derivative $f$ ' similar to the function $f$ (Borji, Font, Alamolhodaei \& Sánchez, 2018).

In the studies by Berry and Nyman (2006) and Ubuz (2007) it was recognized that students have difficulties connecting the graphical representation of the function and that of its derivative and, especially in Ubuz (2007), it was difficult for students use graphic information to give meaning to symbolic representations. Pino-Fan, Guzmán, Font and Duval (2017) reported that a student presents difficulties in connecting symbolic and graphic representations of the absolute value function and deficiencies to work derivate from said function. Likewise, Sánchez-Matamoros, García and Llinares (2008) and Pino-Fan, Godino and Font (2018) mentioned that preservice teachers have difficulties connecting partial meanings of the derivative. Fuentealba, Badillo, SánchezMatamoros and Cárcamo (2018) and Fuentealba, Badillo and Sánchez-Matamoros (2018; 2019) said that students do not understand the derivative because they have difficulties in relating both the growth and decrease of $f$ and the sign of $f^{\prime}$ and $f^{\prime}$ ', and deal with graphic information and the punctual analytical meaning of the derivative. The pre-service teachers have some rote-learning based pieces of knowledge from textbooks in relation with the derivative (Yavuz-Mumcu, 2018). In García-García and Dolores-Flores (2019) it is evidenced that high school students to graph the derivative of a given function graphically, require previously the algebraic representation associated with it, otherwise they would not graph the derivative function. Also, the graphical approach of the derivative has been worked in Moru (2020) through the APOS theory, who identified that the mental constructions of the students about the derivative are generally actions and the coordination of processes on the derivative as limit is mainly in the algebraic register and not in the graphic register, for which it is suggested that the tasks proposed on the derivative require translation from one mode of representation to another.

Furthermore, Herbert and Pierce (2011) reported that in the teaching and learning processes of functions, emphasis should be placed on alternative representations, given that students do not achieve the same understanding in different representations or contexts of the concept of rate. Eli, Mohr-Schroeder and Lee (2011) argued that future teachers have difficulties teaching geometric concepts, due to the lack of connections between mathematical domains, for example, relating the area of the circle in its symbolic representation with the graphical representation of a curve and particularly, most future teachers did not make connections between different representations of a function (algebraic/geometric). Moon et al. (2013) affirmed that future secondary school teachers have cognitive difficulties on the subject of conical curves (i.e., Cartesian connection, graph as a geometric place of points), which did not allow them to make connections between representations.

According to the literature review, we have identified that students, PSMTs and some teachers in service, have difficulties to connect derivative meanings and different representations (verbal, graphic, symbolic, etc.). We believe that, if PSMTs make connections of representations and meanings they could achieve better understanding and solve problems associated with the derivative consistently. Taking into account the problem with connections, we think that it is a relevant topic to be investigated, therefore, the aim set for this research was to analyze the mathematical connections that make PSMTs when solving tasks that involve problems related to the derivative. 
The contributions given by this research are: 1) mathematical connections made by PSMTs when they solve tasks that involve the derivative. 2) The results show situations where PSMTs have difficulties in solving the proposed tasks and evidence is given of the factors that cause these difficulties. 3) The impact that mathematical connections of meaning and different representations have to solve tasks on the derivative, which, according to the literature, these connections are difficult for high school students, PSMTs and in-service teachers to make.

\subsection{Conceptual framework}

In this research, a mathematical connection is understood as "a cognitive process through which a person relates two or more ideas, concepts, definitions, theorems, procedures, representations and meanings with each other, with other disciplines or with real life" (García-García \& Dolores-Flores, 2018, p. 229). In addition, it has been considered that there are models to characterize mathematical connections, for example, the one proposed by Businskas (2008), which has been used more frequently in mathematical connections research. Mathematical connections can be intra-mathematical connections which "are established between concepts, procedures, theorems, arguments and mathematical representations of each other" (Dolores-Flores \& García-García, 2017, p. 160), and extra-mathematical connections which "establishes a relationship of a mathematical concept or model with a problem in context (not mathematical) or vice versa" (Dolores-Flores \& García-García, 2017, p. 161). In this research we focus only on intra-mathematical connections because including extra-mathematical connections would imply working with another theoretical approach to mathematical modeling theory. The expected mathematical connections are: four (procedural, part-whole, implication, and different representations) of Businskas (2008), one (feature) of Eli, Mohr-Schroeder and Lee (2011) and two (meaning and reversibility) of García-García \& Dolores-Flores $(2018 ; 2019 ; 2020)$. These mathematical connections are described below:

1) Procedural: This mathematical connection is evident when rules, algorithms or formulas are used to arrive at a result (García-García, 2019; García-García \& Dolores-Flores, 2019). For example, if a line is not vertical and $P_{1}\left(x_{1}, y_{1}\right)$ and $P_{2}\left(x_{2}, y_{2}\right)$ are points other than the line, then the slope of the line can be found using the formula $m=\frac{y_{2}-y_{1}}{x_{2}-x_{1}}$, with $x_{2}-x_{1} \neq 0$ (Rees, Sparks \& Rees, 1991).

2) Part-whole: This type of connection occurs when someone establishes logical relationships between mathematical concepts: generalization ( $\mathrm{A}$ is a generalization of $\mathrm{B}$, where $\mathrm{B}$ is a particular case of $\mathrm{A}$ ) or inclusion (A is part of B or B is contained in A) (Businskas, 2008; García-García, 2019). For example, the function $g(x)=x^{3}-3 x^{2}-4 x+12$ is a particular case of the general expression $f(x)=a x^{3}+b x^{2}+c x+d$. These relationships can be of inclusion when a mathematical concept is contained in another.

3) Implication: This type of connection is a logical relationship if-then $(\mathrm{A} \rightarrow \mathrm{B})$ (Businskas, 2008; Mhlolo, 2012; García-García, 2018). The procedure that exists in this relationship is presented through logical reasoning in mathematics that suggests connections of an if-then nature. Mhlolo (2012) argues that, in deductive reasoning, the conclusion is reached from previously known facts (the premises). An example of this type of connection is: if $f$ is differentiable in $x=a$, then $f$ is continuous in $x=a$.

4) Different representations: can be alternate or equivalent (Businskas, 2008). That is a mathematical connection is alternate if a student represents a mathematical concept in two or more different ways in different registers of representation: graph-algebraic, verbal-graph, etc. For example, an alternate representation of $y=m x+b$ is straight line geometrically. For its part, an equivalent representation is a transformation within the same register (algebraic-algebraic, graph-graph, symbolic-symbolic, etc.). For example, $P(x)=x^{3}-3 x^{2}-$ $4 x+12$ is equivalent to $P(x)=(x-3)(x-2)(x+2)$ in the algebraic register. In terms of semiotic representations theory, alternate representations refer to conversions and representations equivalent to treatments (Duval, 2006).

5) Feature: It is identified when the subject manifests some characteristics of the concepts or describes its properties in terms of other concepts that makes them different or similar to others (Eli et al., 2011; GarcíaGarcía \& Dolores-Flores, 2019). For example, when the person mention some elements of a polynomial function $f(x)=a_{n} x^{n}+a_{n-1} x^{n-1}+a_{n-2} x^{n-2}+\cdots+a_{0}$ (derivative function or antiderivative function) are coefficients (all, $a_{i}$, with $i=0,1,2,3, \ldots, n$ ), literal or variables (in this case, the " $x$ ") and exponents of the variables $(n, n-1, n-2, \ldots, 1)$ (García-García \& Dolores-Flores, 2019).

6) Meaning: This mathematical connection is presented "when students attribute a meaning to a mathematical concept as long as what it is for them (which makes it different from another) and what it represents; it can include the definition that they have built for these concepts" (García-García, 2019, p. 131). In this sense, students express what the mathematical concept means to them, including their context of use or their definitions (García-García, 2019). In this research, we assume that this type can be more general, that is, we accept the existence of a mathematical connection between meanings. We consider that this type is manifested when the students relate different meanings attributed to a concept to solve a specific problem. The derivative $f^{\prime}(a)$ is the instantaneous rate of change of $y=f(x)$ with respect to $x$ when $x=a$ (Stewart, 1999, p. 153). 
7) Reversibility: It is present when a subject starts from a concept $\mathrm{A}$ to get to a concept $\mathrm{B}$ and invert the process starting from B to return to A (García-García \& Dolores-Flores, 2019). For example, this connection is established when the bidirectional relationship between derivative and integral, as operators, is recognized and when the Fundamental Theorem of Calculus is used as a way to link both concepts (García-García \& DoloresFlores, 2018).

Furthermore, García-García and Dolores-Flores (2018) affirm that, "mathematical connections emerge when students solve specific tasks and can identify them in their written productions or in the oral or mimic arguments they develop" (p. 229).

\section{Methodology}

This research is qualitative (Cohen, Manion \& Morrison, 2018), where an adaptation of the semi-structured interview was followed from the point of view of Adams (2015), and the thematic analysis was considered (Braun \& Clarke, 2006).

\subsection{Method of collecting data}

The semi-structured interview and a questionnaire were implemented. The semi-structured interview is a verbal exchange between two people, where one person is the interviewer and other is an interviewee or participant. This type of interview is not based on a protocol or guide questionnaire, but as the conversation flows, questions emerge to explore important issues (Longhurst, 2010). The interview was conducted considering the following stages to design and implement it according to Adams (2015): 1) selecting and recruiting the participants, 2) drafting the questions and interview guide, 3) Starting the interview and techniques for this type of interviewing, and 4) analyzing the information gathered.

\subsubsection{Stage 1. Selecting participants}

The participants were five students of bachelor's degree in mathematics ${ }^{1}$ (PSMTs) at a higher-level school located in the capital of the state of Guerrero, Mexico. They were three male and two females. The participants were volunteers, and we were confirmed that they had taken and passed the Differential Calculus course where the derivative topic is developed. In addition, it was verified that during their training they had a good academic performance (see Table 1).

Table 1. Participants' information

\begin{tabular}{|c|c|c|c|c|c|}
\hline \multirow{2}{*}{ Participants } & \multirow{2}{*}{ Age } & Gender & \multirow{2}{*}{$\begin{array}{l}\text { Bachelor's degree in } \\
\text { mathematics (UAGro) }\end{array}$} & \multirow{2}{*}{ Average } & \multirow{2}{*}{ Semester } \\
\hline & & $\mathrm{F} \quad \mathrm{M}$ & & & \\
\hline $\mathrm{P} 1$ & 21 & $*$ & Yes & 8.68 & 6 \\
\hline $\mathrm{P} 2$ & 21 & $*$ & Yes & 8.77 & 7 \\
\hline P3 & 22 & $*$ & Yes & 9.06 & 7 \\
\hline $\mathrm{P} 4$ & 22 & $*$ & Yes & 9.1 & 7 \\
\hline P5 & 22 & $*$ & Yes & 9.28 & 7 \\
\hline
\end{tabular}

\subsubsection{Stage 2. Drafting the questions and interview guide}

A questionnaire was designed that included three tasks (see Table 2), with the purpose of exploring mathematical connections that students make when solving these tasks, especially those of meaning and different representations (graphic, symbolic, etc.), which are the connections that students do not make, PSMTs and some teachers in service, and for that reason, they fail to understand the derivative as reported in the literature review. This instrument was validated by experts (a teacher of Differential Calculus and a researcher on the subject of mathematical connections). Also, three undergraduate students in mathematics were applied to determine the affordability of tasks.

\footnotetext{
${ }^{1}$ The Bachelor of Mathematics that the students where the data was collected consists of eight semesters. In Mexico, the numerical scale of grades is from 0 to 10 . In some university schools (as in the school where this res earch was done), the minimum passing grade is 7 .
} 
Table 2. Tasks proposed to the PSMTs

Task 1. What does the derivative mean to you? Explain your answer.

Task 2. Given the function $\boldsymbol{f}(\boldsymbol{x})=\frac{x^{2}}{\mathbf{4}}+\boldsymbol{x}+\mathbf{5}$,

a) Find the equation of the tangent line to the graph of the function at $\boldsymbol{x}=\mathbf{4}$.

b) Determine the tangency point.

Task 3. The productivity $\boldsymbol{p}$ of a farmer in one hour is given by $\boldsymbol{p}=\mathbf{3 0 0 t}(\mathbf{1}-\boldsymbol{t})$ where $\boldsymbol{t}$ is time in hour and $\mathbf{0} \leq \boldsymbol{t} \leq \mathbf{1}$. Considering the previous information, answer: (a) At what times does productivity increase or decrease? (b) At what times is productivity maximum? (c) At what times is productivity null? Argue your answer.

Subsequently, the questionnaire was previously applied to the five students (participants), in order to obtain their written productions, which were reviewed by the authors of this article. In this review, some questions emerged to clarify some answers, for example, explain what does the derivative mean? In addition to the meaning given, are there others? Explain the procedure used to find the tangent line to the curve and why is the derivative used? Explain when productivity is maximum or null?

\subsubsection{Stage 3. Starting the interview and techniques for this type of interviewing}

The interview was motivated to know how the PSMTs solved the tasks. Before the interview began, the PSMTs were asked to be willing, and they also agreed to use a video camera to capture the PSMTs' arguments when solving the tasks. In this sense, since the interviewer (First author) interacted with each pre-service mathematics teacher (PSMT) separately. Adams (2015) suggests that it is important to use this type of interview "if you need to ask probing, open-ended questions and want to know the independent thoughts of each individual" (p. 494). Also, in the middle of the interview, field notes were taken, where key annotations (evidence of a mathematical connection) were made about the participants' responses. The interviews lasted two hours for each participant.

\subsubsection{Stage 4. Analyzing the information (thematic analysis).}

Data analysis was developed from the thematic analysis that is a data analysis method that allows to identify, organize and describe in detail patterns understood as themes (Braun \& Clarke, 2006). The six analysis phases that must be carried out are described below (Braun \& Clarke, 2006; Nowell, Norris, White \& Moules, 2017), see Table 3:

Table 3. Description of the thematic analysis phases

\begin{tabular}{|c|c|c|}
\hline & Phases & Description of the phase \\
\hline First & $\begin{array}{l}\text { Familiarizing } \\
\text { yourself } \\
\text { with your data }\end{array}$ & $\begin{array}{l}\text { The information obtained after the application of the interviews was } \\
\text { transcribed and left in the text form in order to obtain familiarity with the } \\
\text { data. }\end{array}$ \\
\hline Second & $\begin{array}{l}\text { Generating initial } \\
\text { codes }\end{array}$ & $\begin{array}{l}\text { Words and phrases were identified in the data that indicated some } \\
\text { mathematical connections to generate initial codes. }\end{array}$ \\
\hline Third & $\begin{array}{l}\text { Searching for } \\
\text { Subthemes and } \\
\text { themes }\end{array}$ & $\begin{array}{l}\text { Subsequently, themes were searched, which are made up of codes that had } \\
\text { similar characteristics. In this research, the themes are the types of a priori } \\
\text { mathematical connections described in the conceptual framework. }\end{array}$ \\
\hline Fourth & $\begin{array}{l}\text { Reviewing } \\
\text { Subthemes and } \\
\text { themes }\end{array}$ & $\begin{array}{l}\text { Subthemes y themes identified in the previous phase were reviewed and } \\
\text { triangulated by experts. This triangulation helped to remove or form new } \\
\text { themes from the data. }\end{array}$ \\
\hline Fifth & $\begin{array}{l}\text { Defining and } \\
\text { naming } \\
\text { themes }\end{array}$ & $\begin{array}{l}\text { The identified themes that include their common characteristics were } \\
\text { named. In this phase the investigators came to consensuses on the typology } \\
\text { of mathematical connection that was identified in the data. }\end{array}$ \\
\hline Sixth & Producing the report & $\begin{array}{l}\text { A report is produced, showing the themes (mathematical connections) found } \\
\text { in the analysis. }\end{array}$ \\
\hline
\end{tabular}

Based on the phases of the thematic analysis described in Table 3, the results of the research are presented below. Initially, the first four phases describe the resolution of the PSMTs on task 1. 


\subsubsection{First and second phases of the thematic analysis.}

In the first phase, the interviews were transcribed. Also, the field notes and photographs taken by the authors, as well as the written productions, the oral arguments and the gestures of the participants (P1, P2, P3, P4 and P5) were considered, and the data was triangulated (Carter, Bryant-Lukosius, DiCenso, Blythe \& Neville, 2014). In the second phase, the codes (C) in the transcripts were identified as shown in Table 4. As an example, only relevant codes extracted from the responses to task 1 will be shown, where words and phrases were identified where the mathematical connections.

Table 4. Excerpts from the transcript of the interview with the participants $(\mathrm{P})$ when they solved task 1

\begin{tabular}{|c|c|c|}
\hline $\mathrm{P}$ & Codes & Excerpt from transcription (evidence of codes) \\
\hline \multirow[b]{2}{*}{ P1 } & $\mathrm{C} 1$ & The derivative is the tangent line to a function. \\
\hline & C2 & $\begin{array}{l}\text { The derivative is the limit of a function plus an increment minus the original function between } \\
\text { the increment. }\end{array}$ \\
\hline \multirow[b]{2}{*}{$\mathrm{P} 2$} & $\mathrm{C} 3$ & The derivative is the slope of the tangent line at a point. \\
\hline & $\mathrm{C} 4$ & $\begin{array}{l}\text { The derivative is the limit, when we have } \Delta x \rightarrow 0 \text { of the limit of the function } f(x) \text { plus the } \\
\text { increment }(\Delta x) \text {, minus the original function between }(\Delta x) \text {, that is the definition. }\end{array}$ \\
\hline \multirow[b]{3}{*}{ P3 } & $\mathrm{C} 5$ & A limit of $\Delta x$ when it tends to zero of $f(x)$ plus $\Delta x$ minus $f(x)$ between $\Delta x$. \\
\hline & C6 & The derivative represents the slope of the tangent line at a point. \\
\hline & $\mathrm{C} 7$ & $\begin{array}{l}\text { The derivative is that both the value of } y \text { changes with respect to } x \text {, that is, an increase or } \\
\text { decrease in how much } y \text { varies with respect to } x \text { and the function evaluated at that point } x \text { is } \\
\text { the image. }\end{array}$ \\
\hline \multirow[t]{2}{*}{$\mathrm{P} 4$} & $\mathrm{C} 8$ & $\begin{array}{l}\text { The limit of a quotient that meets certain conditions, when we set a point } P_{0} \text { on the curve and } \\
\text { make another point } P \text { that is variable on the curve, then we draw a line that passes through } \\
\text { those two points and what comes next is that the } P \text { since it can move along the curve then it } \\
\text { can move closer to } P_{0} \text {, so as } P \text { tends to } P_{0} \text { a line is formed which is called a tangent, so this } \\
\text { tangent makes an angle with the } x \text { axis, has a tangent, so this is given that the slope of the line } \\
\text { is going to be equal to the tangent of the angle. }\end{array}$ \\
\hline & C9 & So, the derivative is going to be the slope of the tangent line at a point. \\
\hline \multirow[b]{4}{*}{ P5 } & $\mathrm{C} 10$ & The derivative can be expressed as the slope of the tangent line of a curve a \\
\hline & $\mathrm{C} 11$ & The derivative in Calculus is defined as $\lim _{\Delta x \rightarrow 0} \frac{f(x+\Delta x)-f(x)}{\Delta x}$. \\
\hline & $\mathrm{C} 12$ & The derivative can be used to measure whether a function is increasing or decreasing. \\
\hline & $\mathrm{C} 13$ & $\begin{array}{l}\text { In differential Geometry, we use the derivatives of a function to determine the trihedron of a } \\
\text { curve. When we have a curve in the third dimension, it is important to associate a reference } \\
\text { plane to each point of the curve, and this is made up of, tangent vector, normal vector and } \\
\text { binormal vector. }\end{array}$ \\
\hline
\end{tabular}

\subsubsection{Third and fourth phases of the thematic analysis.}

Subsequently, from Table 4 the codes were grouped into subthemes (third phase). In this process of assigning themes, similarities, characteristics, and meanings associated with the derivative that the participants gave in common were taken into account, which is considered a mathematical connection of meaning and different representations (see Table 5, Figures 1 and 2).

It is important to mention that, in the same argument offered by the PSMT (in this case P5) it is possible to identify more than one mathematical connection. For example, by the production of the PSMT we identify in $\mathrm{C} 10$ and in $\mathrm{C} 11$ the connections of different meaning and representations (see Table 5).

\subsubsection{Fifth and sixth phases of the thematic analysis.}

In the fifth phase in repeated work meetings, the authors defined the themes identified in correspondence with the conceptual framework adopted in this work. Subsequently, in the sixth phase, the report of the results is presented, showing the identified mathematical connections (see section 3). 
Table 5. Assignment of subthemes and themes

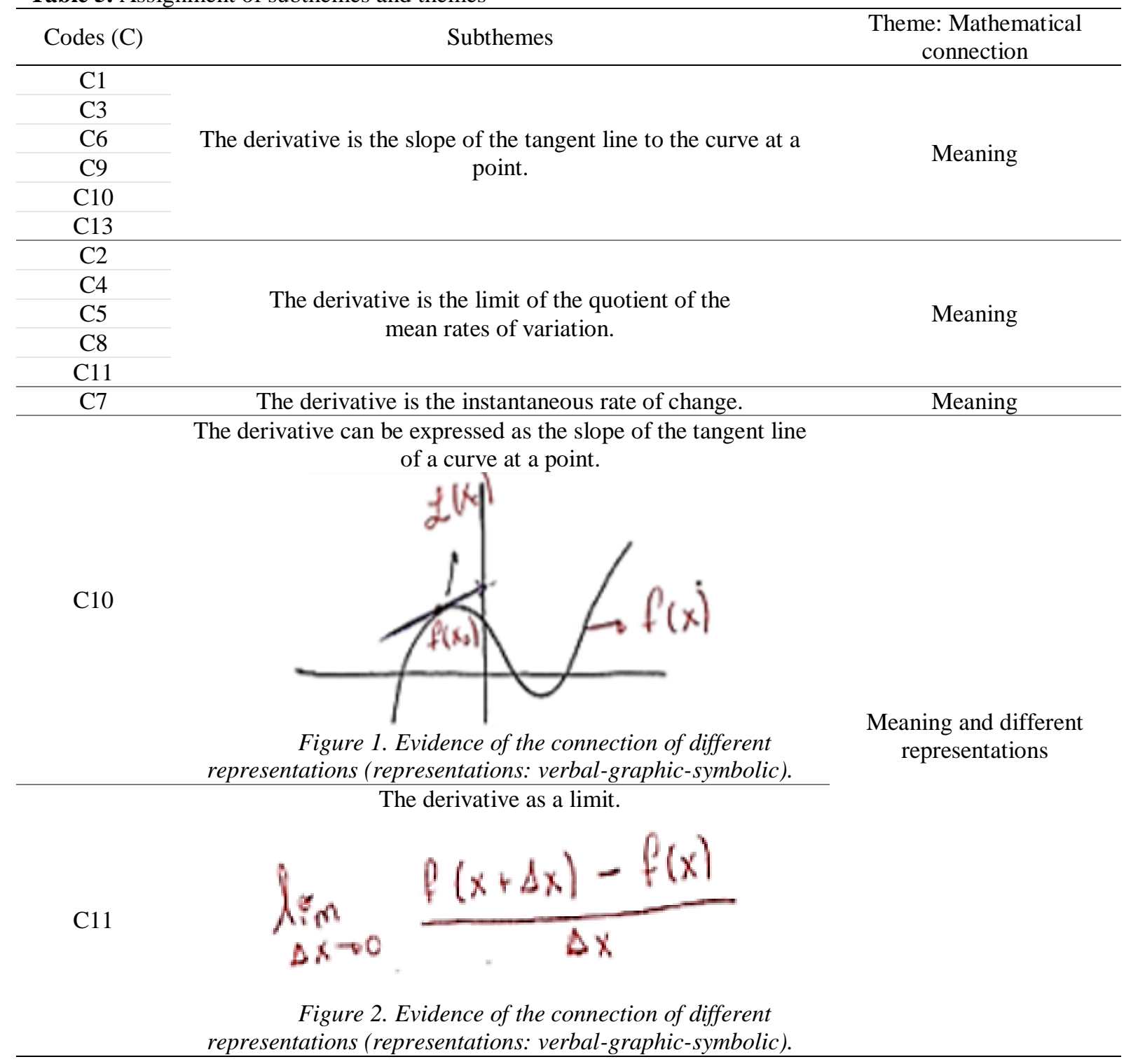

\section{Results}

The analysis of the data allowed us to identify the mathematical connections that the PSMTs made when they solved the proposed tasks.

\subsection{Mathematical connections of Meaning type}

The mathematical connection of the meaning of the derivative was evidenced as the slope of the tangent line to the curve at a point, as the limit of the quotient of the mean rates of variation of the function, and as the instantaneous rate of change. In this sense, the participants associated a meaning to the derivative term as presented in Figures 3, 4 and 5, where the mathematical connection scheme of meaning suggested in RodríguezNieto et al. (2020), in which the derivative mathematical concept is related to its meaning through a code or argument that supports them.

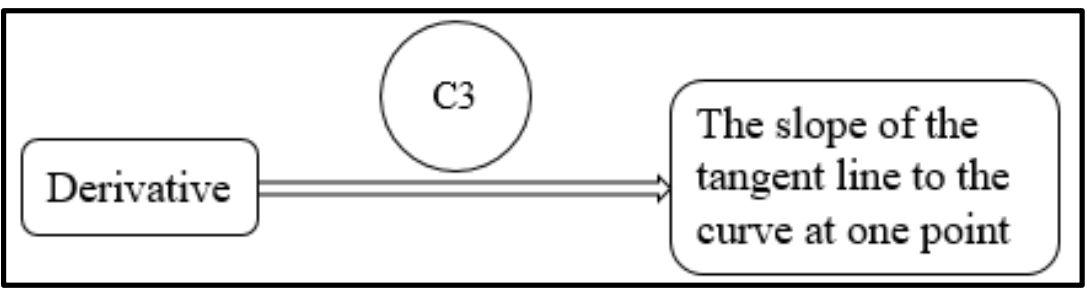

Figure 3. Mathematical connection of meaning type 
Participants P2, P3, P4 and P5 made the mathematical connection as presented in Figure 2. However, P1 only mentioned part of the meaning of the derivative, which does not allow it to be called a mathematical connection, that is, of the way P1 interprets the derived concept, could apply it in problem-solving. Also, in this case it would be necessary to mention the "slope". The other mathematical connection of meaning revolves around the definition of the derivative as the limit of the incremental quotient (see Figure 4). In this case, all participants made it.

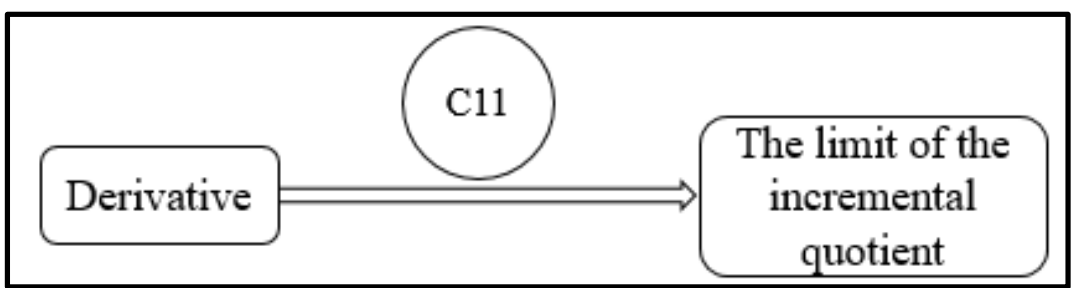

Figure 4. Mathematical connection of meaning type

Likewise, we evidenced that P3 expressed the meaning of the derivative as the instantaneous rate of change (see Figure 5).

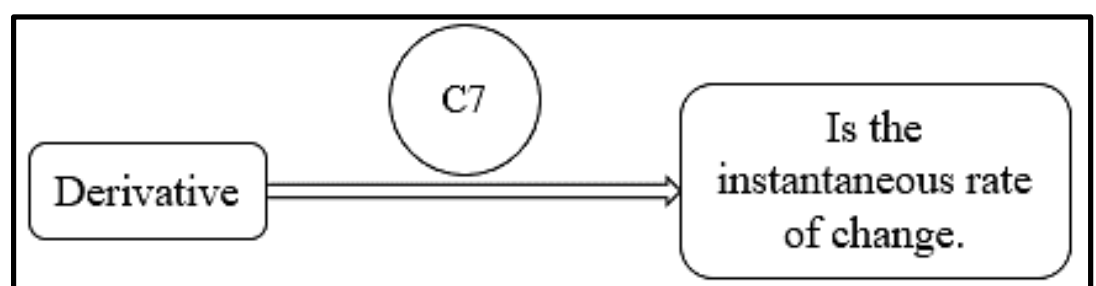

Figure 5. Mathematical connection of meaning type

In the PSMTs' productions associated with the mathematical connection of meaning of the derivative, other mathematical connections were also identified, such as that of different representations and that of part-whole. Now, in codes $\mathrm{C} 12$ and C13, P5 referred to uses of the derivative to find the trihedron of a curve, locating itself in the mathematical connection of meaning (see Figure 6). In the case of a resolution to task 1, other mathematical connections of different representations and part-whole types can be evidenced.

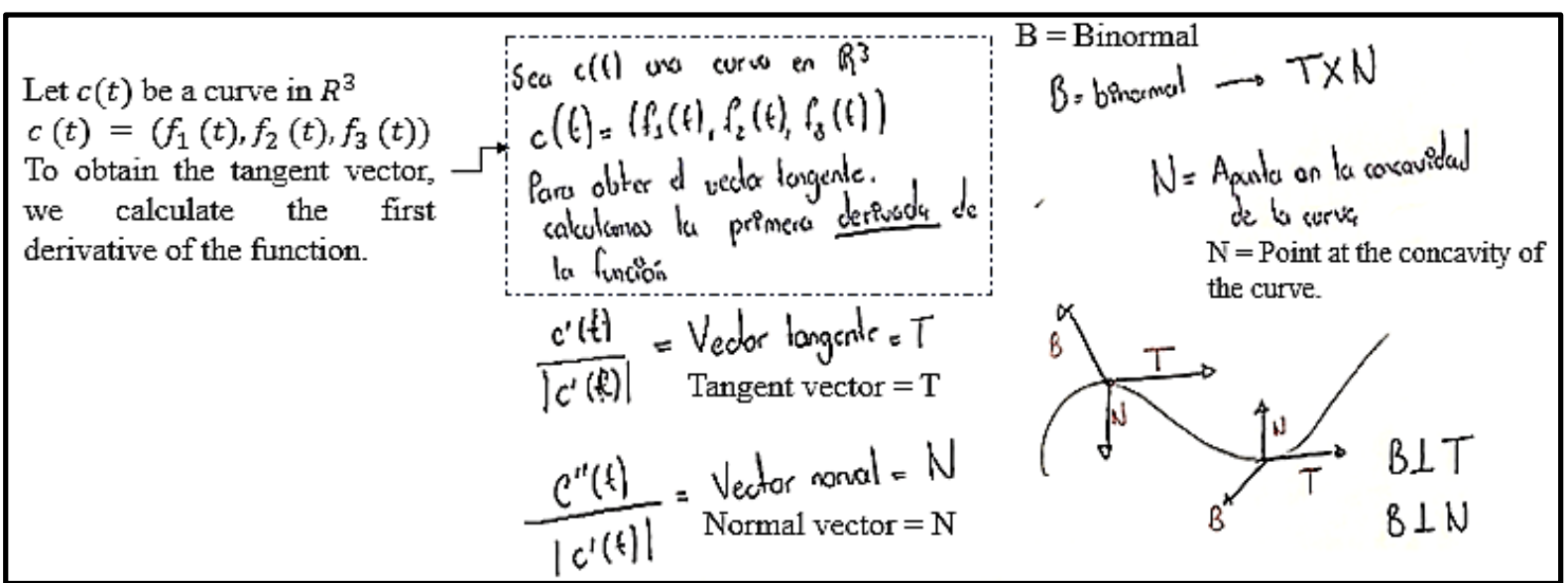

Figure 6. Using the derivative to find the tangent vector (mathematical connection of meaning type)

\subsection{Mathematical connections of Different representations type}

In codes $\mathrm{C} 8$ and $\mathrm{C} 9, \mathrm{P} 4$ associated the following different representations with the derived term (see Figure 7). The mathematical connection between the symbolic representation $\lim _{\Delta x \rightarrow 0} \frac{f(x+\Delta x)-f(x)}{\Delta x}$ and the graph where the derivative is drawn as the slope of the tangent line. Likewise, it is confirmed that these representations are connected to the verbal language representation obtained in the excerpts from the interviews and is evidenced in C8 and C9 of Table 4. 


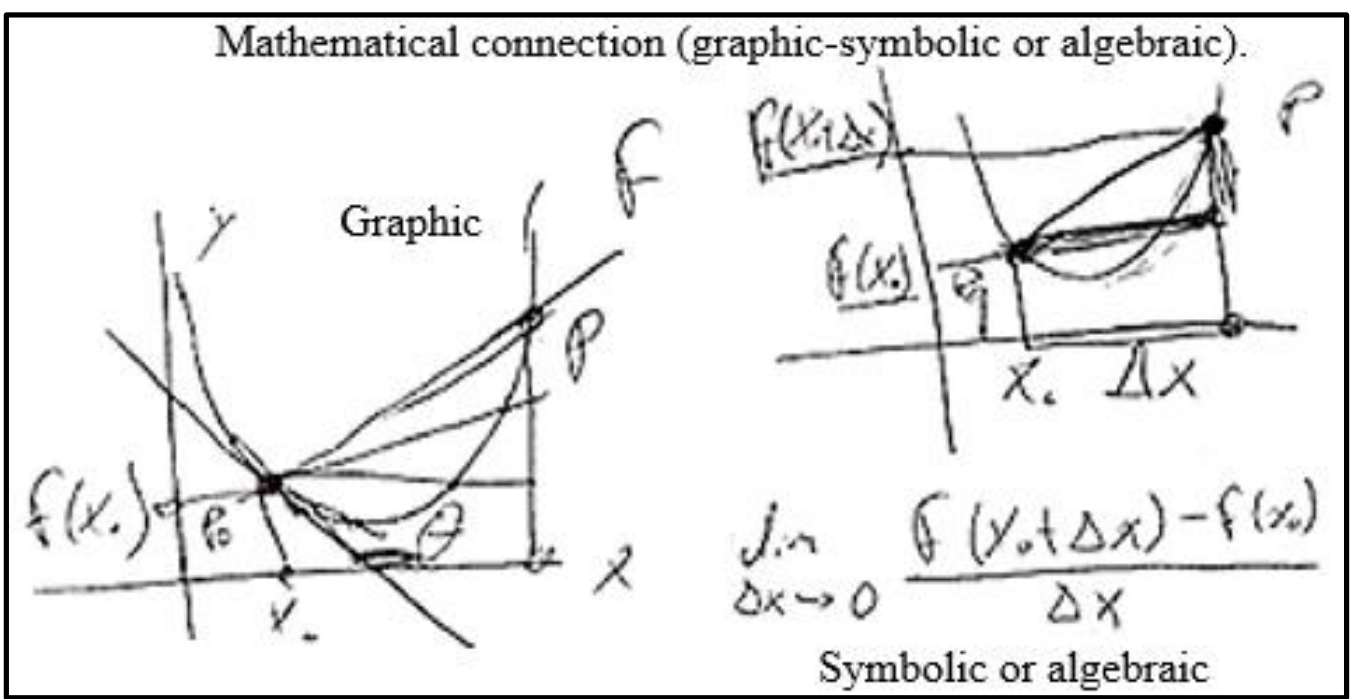

Figure 7. Mathematical connection between different representations of the derivative

Likewise, P5 used different representations (verbal, graphic, and symbolic) when expressing their meanings of the derivative (see Figure 8).

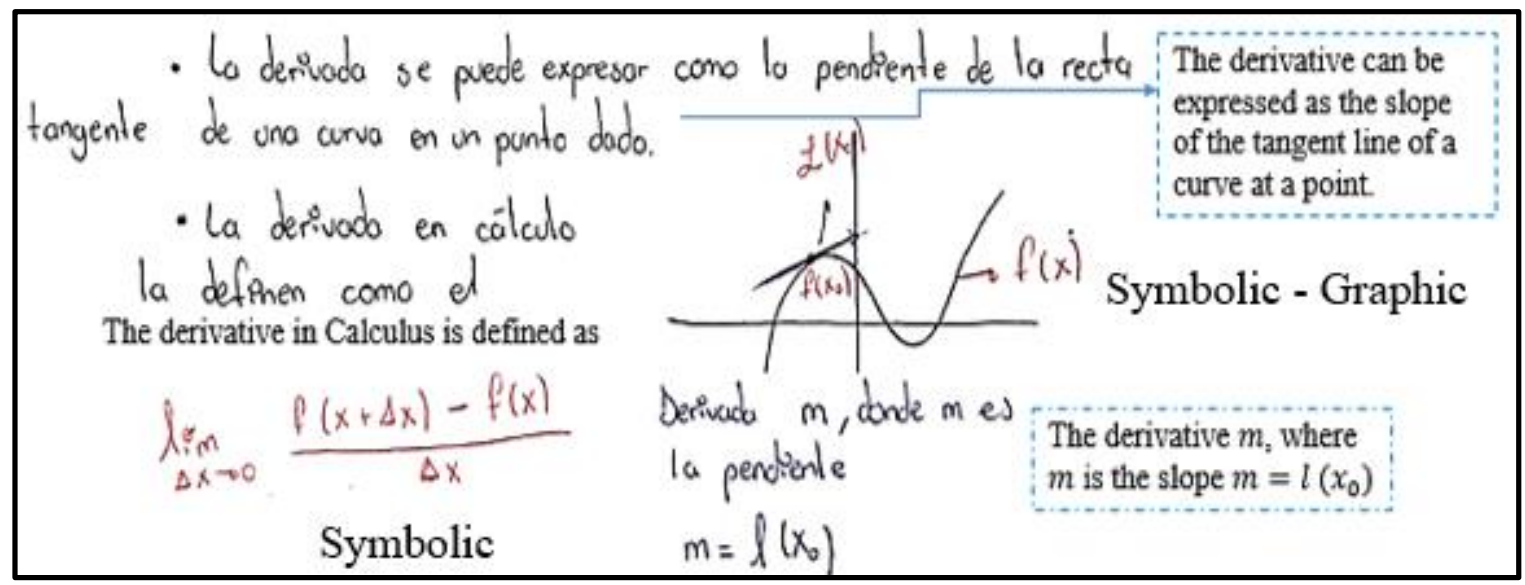

Figure 8. Mathematical connections between different representations

In the resolution of task 2, the participants made the mathematical connection of different representations. For example, P5 used symbolic, graphical, tabular, and verbal or written representations (see Figure 9). In addition, the type of representations is consistent with that is mathematically accepted, that is, its procedure is correct.

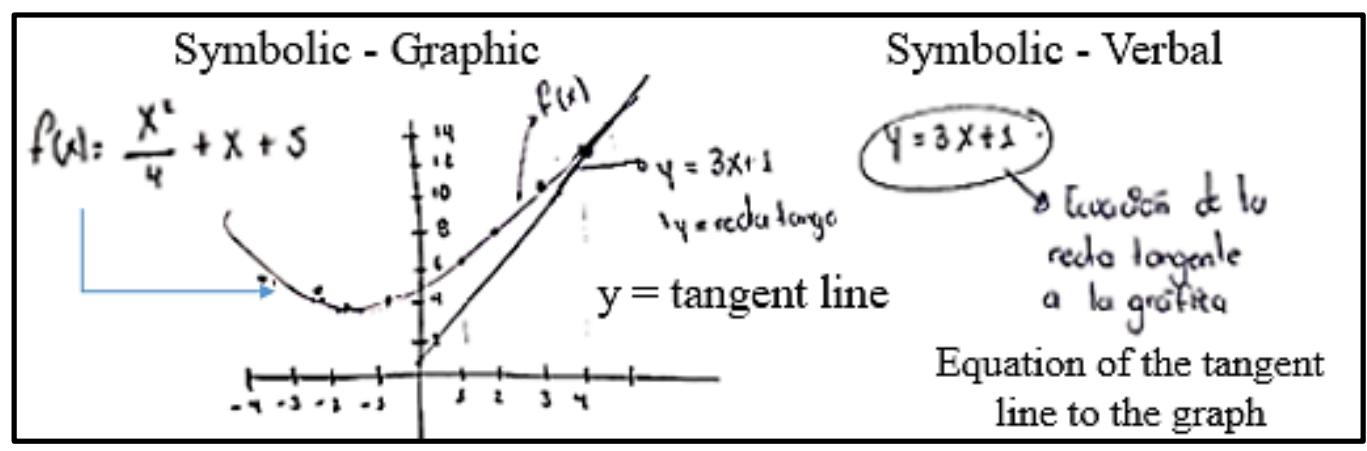

Figure 9. Mathematical connections of different representations type

Also, in the resolution of task 3, the participants made mathematical connections between different representations (alternate, that is, graph-algebraic). For example, P3 and P4 made different representations (equivalents: $p=300 t(1-t)$ and $p=-300 t^{2}-300 t$ ), as well as graph-algebraic when sketching the graph of the function. The mathematical connection of different representations is said to be equivalent when multiplying the factors of the factored expression $p=300 t(1-t)$, obtaining $p=300 t-300 t^{2}$. In this sense, 
Gagatsis and Shiakalli (2004) stated that "ability to translate from one representation of the concept of function to another promotes problem-solving success" (p. 655).

\subsection{Mathematical connections of Procedural type}

These types of mathematical connections were identified when P5 used the formula to derive the polynomial function and later replaced the abscissa $x=4$ in the algebraic expression of the derivative $f^{\prime}(x)=\frac{x}{2}+1$ to find the value of slope $m=3$. At another time, the connections emerged when P5 used the point-slope formula to find the equation of the tangent line that was asked in task 2. It should be noted that participants P2 and P4 managed to establish this type of mathematical connections. For example, Figure 10 describes the procedural type mathematical connections made by P5.

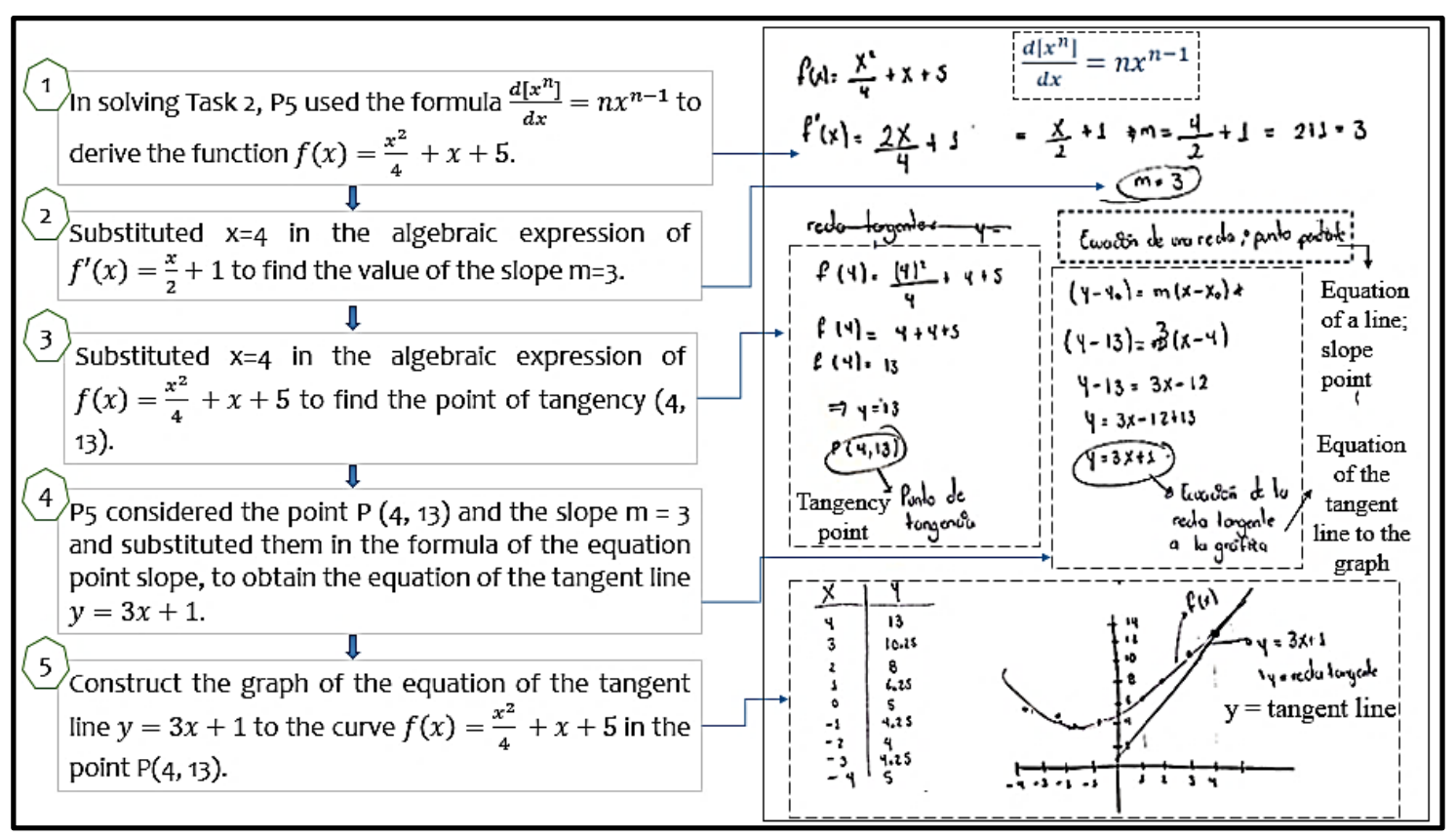

Figure 10. Description of the mathematical connections of procedural type

In Task 3, P2 made mathematical connections between different representations (equivalents: $p(t)=300 t(1-t)$ and $p(t)=300 t-300 t^{2}$, arguing that productivity increases when $t$ (time) takes values above zero and productivity decreases when $t$ takes values close to one and begins to decrease when $t>0.5$. P 4 made the procedural connection when he substituted $t=0.5$ in the algebraic expression of p obtaining that the maximum productivity is 75 . Subsequently, again $\mathrm{P} 4$ made mathematical connections of procedural type to find the values where productivity is zero $x=0$ and $x=1$ using the general formula. Then, he derived the function finding that the maximum of the function is given when $t=\frac{1}{2}$ (see Figure 11).

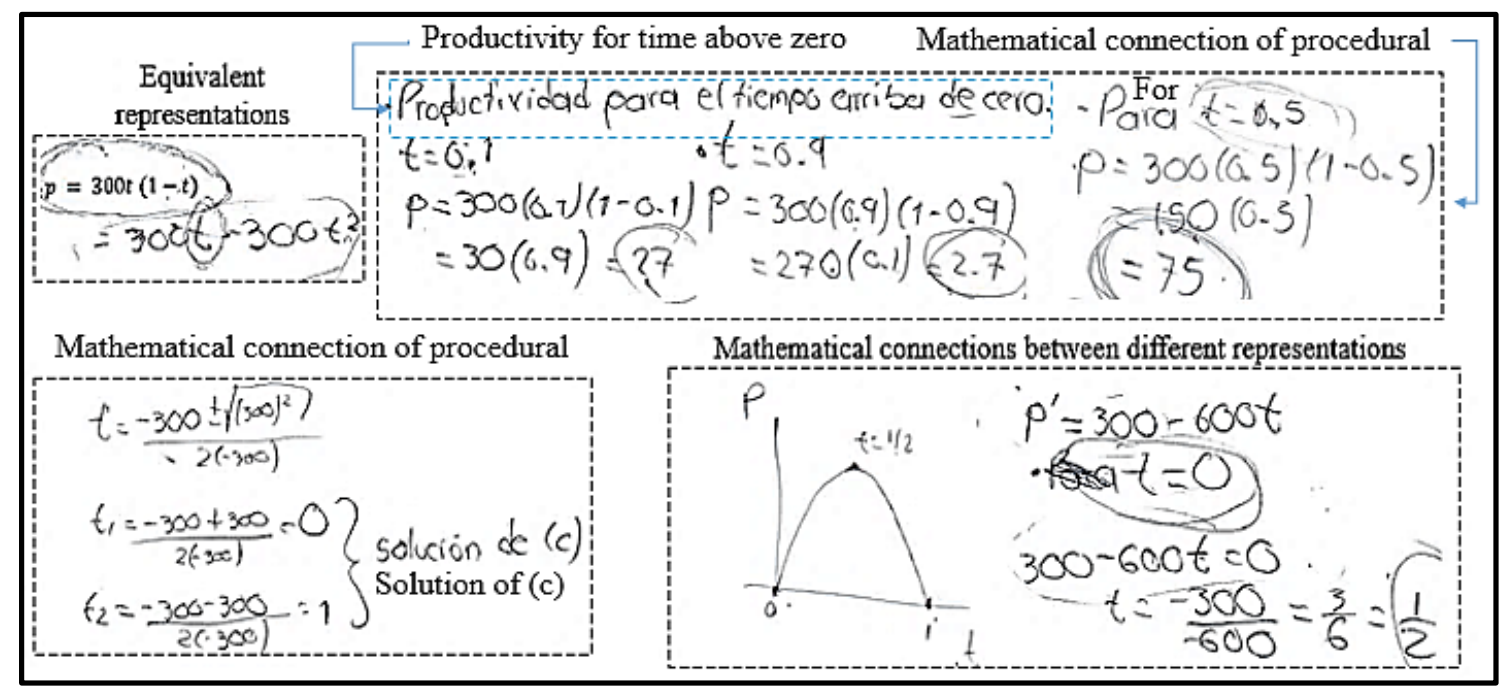

Figure 11. Mathematical connections evidenced in the resolution of task 3 
Finally, P3 considered the derivative to find the value in $t$ for which productivity is maximum, he established procedural mathematical connections when he derived $p=-300 t^{2}-300 t$. Then, he equaled the expression obtained to zero obtaining $t=\frac{3}{6}$ and evaluated this value in the algebraic expression of $p$, obtaining that the maximum productivity is 75 , since when the maximum productivity depends on where the function reaches the relative maximum (see Figure 12 ). Later, he argued that productivity increases in the interval $\left(0, \frac{3}{6}\right)$, decreases in the interval $\left(\frac{3}{6}, 1\right)$ and is null when $t=0$ and $t=1$.

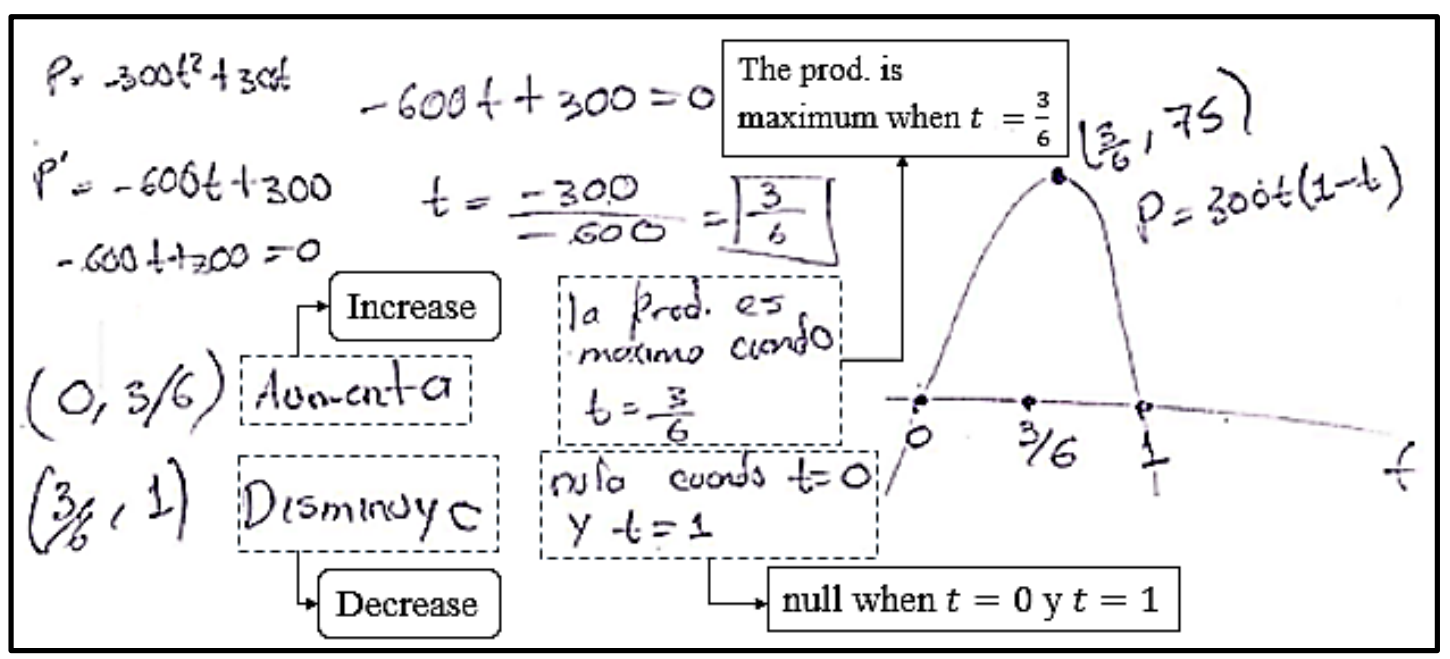

Figure 12. Mathematical connections made in the resolution of task 3

Concerning task 3, initially, P4 analyzed the behavior of the function considering mathematical connections of procedural type (see Figure 13), associating it with a parabola that opens downwards, where it observed that the production increases in the time interval $\left(0, \frac{1}{2}\right)$ and decreases by $\left(\frac{1}{2}, 1\right)$. Also through the mathematical connection of procedural type, $\mathrm{P} 4$ substituted $t=\frac{1}{2}$ in the algebraic expression $p(t)=300 t(1-t)$ and argued that productivity is maximum at $t=\frac{1}{2}$, that is, in the vertex of the parabola (maximum productivity is 75 ). Likewise, $\mathrm{P} 4$ obtained that the productivity is null when $t=0$ or $t=1$.

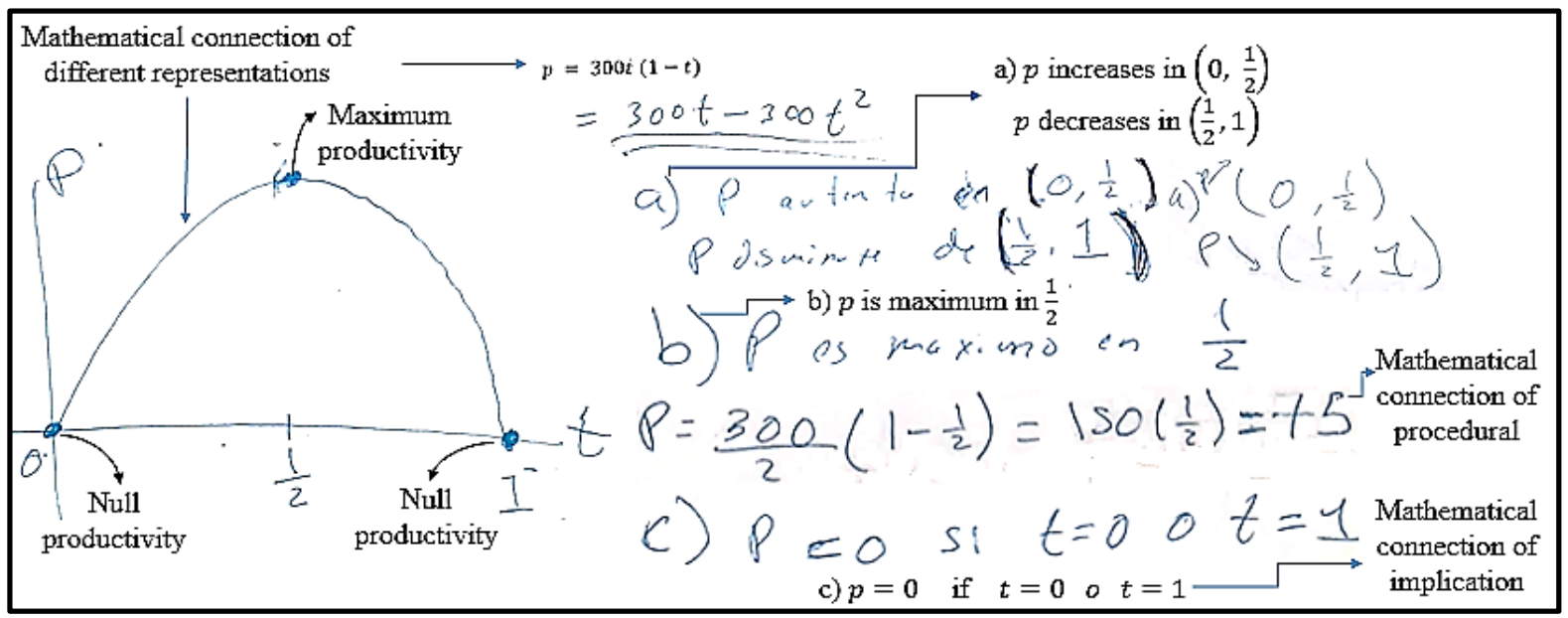

Figure 13. Mathematical connections of procedural type

In the same way that P2, P3 and P5 made procedural connections when it mentioned it derived the expression $p=-300 t^{2}-300 t$ and then, equaled it to zero leading it to affirm that productivity is maximum when $t=$ 0.5 , the productivity is null when $t=1$ or $t=0$. Also, $\mathrm{P} 2, \mathrm{P} 3, \mathrm{P} 4$ and $\mathrm{P} 5$ argued that productivity decreases as $t$ $\in(0.5,1)$ and increases when $t \in(0,0.5)$, see Figure 14 . 


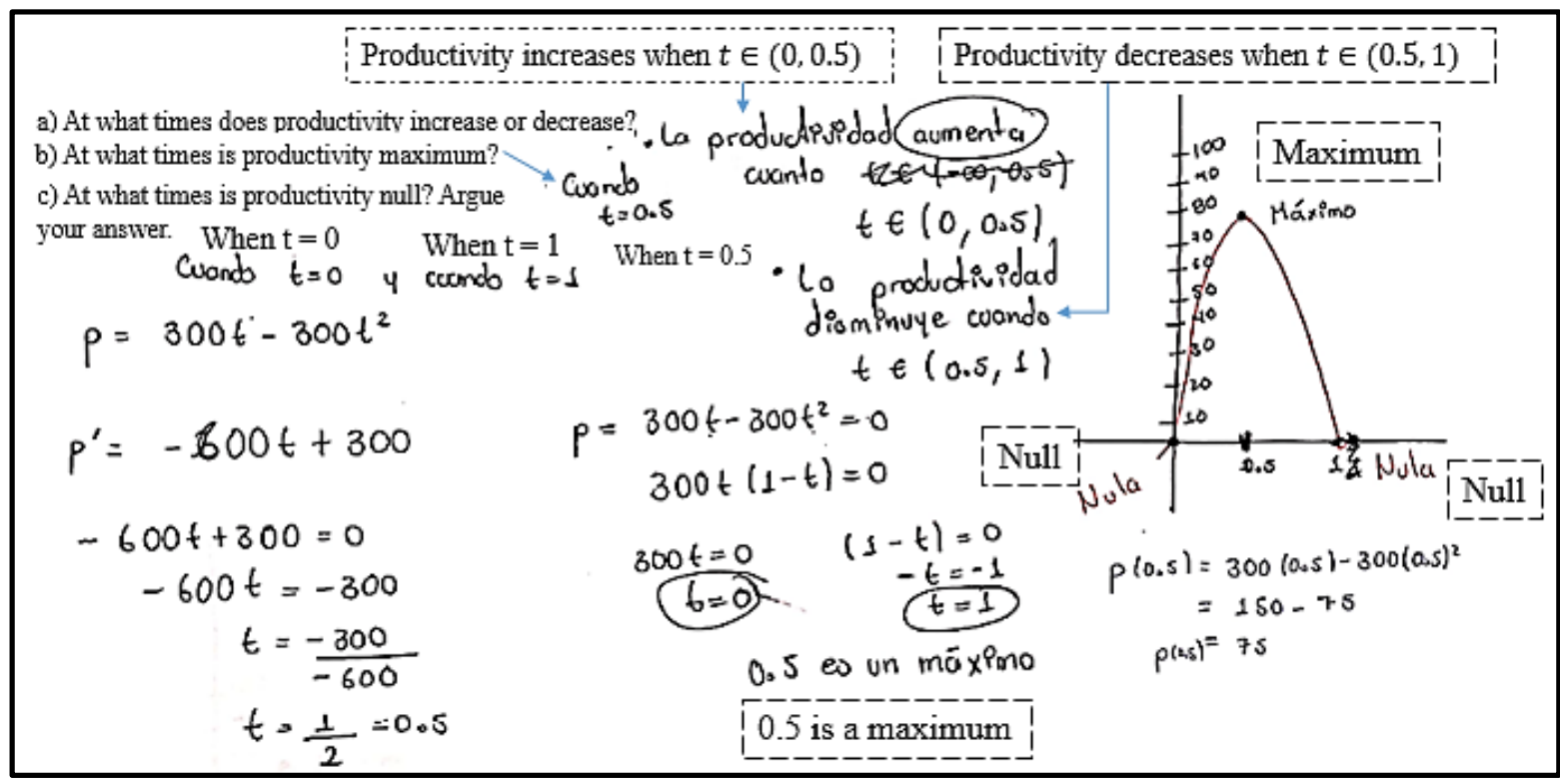

Figure 14. Mathematical connection of procedural type

It is important to mention that the statements of the PSMTs when deciding whether productivity is maximum or null, are supported by logical or implication relationships that help interpret and solve application problems in mathematical terms.

\subsection{Mathematical connections of Implication type}

The mathematical connection of implication emerged in the resolution of task 3 , where the participants affirmed that, if the productivity is null then $t=0$ or $t=1$; If productivity is maximum then $t=0.5$. That is, productivity is maximum when there is a relative maximum (see Figures 11, 12, 13 and 14).

\subsection{Mathematical connections of Part-whole type}

In most cases it is inferred that the part-whole mathematical connection emerged, where participants used parts of a graph. For example, in Figures 11, 12, 13 and 14, participants only outlined the positive part of the graph $p=300 t(1-t)$. Likewise, in Figure 9, P1 only considered part of the graph of the function $f(x)=\frac{x^{2}}{4}+$ $x+5$. Also, this type of mathematical connection was identified when the participants analyzed the behavior of the graph of the function, showing the increase and decrease of the function associated with the behavior of productivity at specific intervals (see Figure 15). In addition, they indicated points that belong to the graph, in which productivity is maximum or null, giving evidence of part-whole relationships (inclusion).

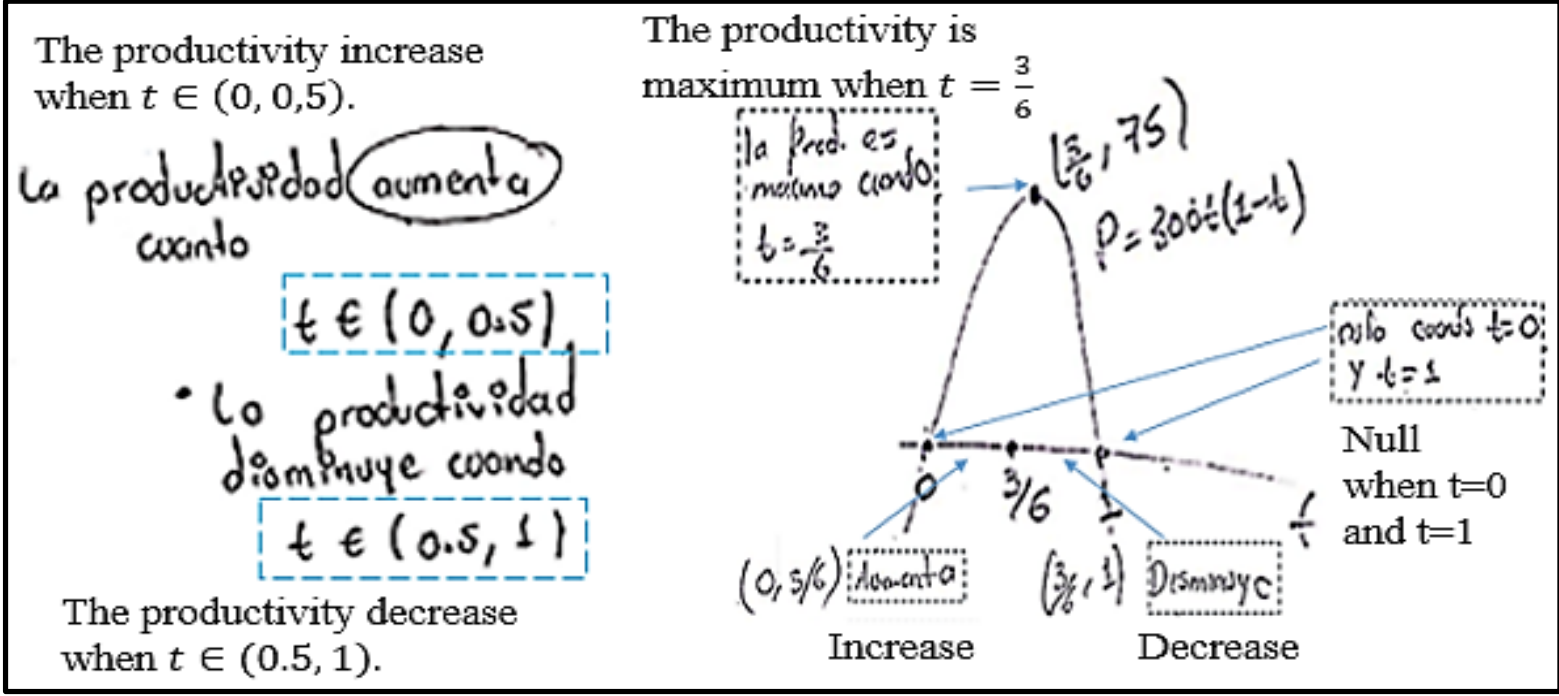

Figure 15. Mathematical connection of part-whole type in solving task 3 
In the same way, as it is presented in Figure 16, it is observed in Figures 12, 13, 14 and 15, where for example the PSMT P5 states that productivity increases in $t \in(0,0.5)$, whose relationship it belongs (partwhole).

\subsection{Mathematical connection of feature type}

This mathematical connection was identified when the students mentioned characteristics or properties of the derivative. For example, in triangulation with an expert researcher on connections, it was recognized that the phrase in P5: "the derivative can be used to measure whether a function is increasing or decreasing" corresponds to a characteristic of the derivative and also the phrase of P1: "the derivative of a polynomial function is a reduction of its degree by one" in principle it had been considered as a connection of meaning, but it is really a feature type connection as evidenced in García-García and Dolores-Flores (2018; 2019). An example of these connections is evidenced in Figure 16.

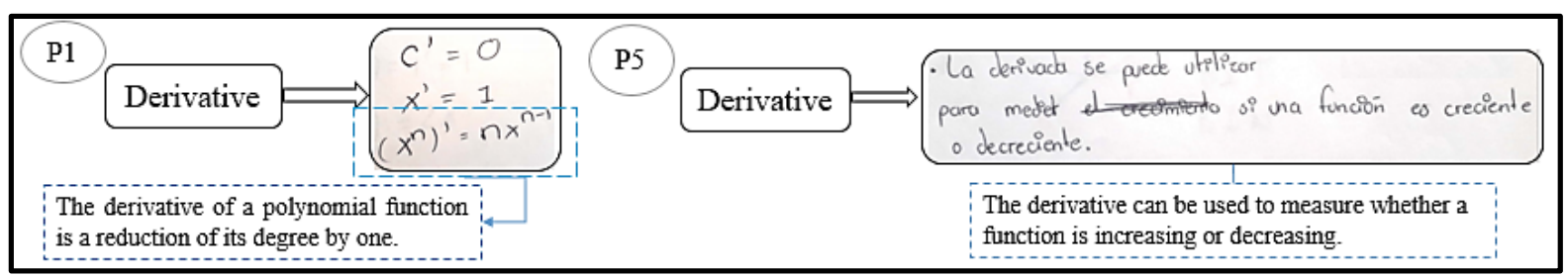

Figure 16. Mathematical connections of feature type

However, in the productions of the PSMTs, some causes were identified that prevented them from establishing mathematical connections. For example, P1 confused the algebraic representation of the derivative with the equation of the tangent line leading him to make errors in the solution of task 2. For this reason, P1 reached an incorrect result, showing the disconnection in the use of different representations and procedural errors (see Figure 17).

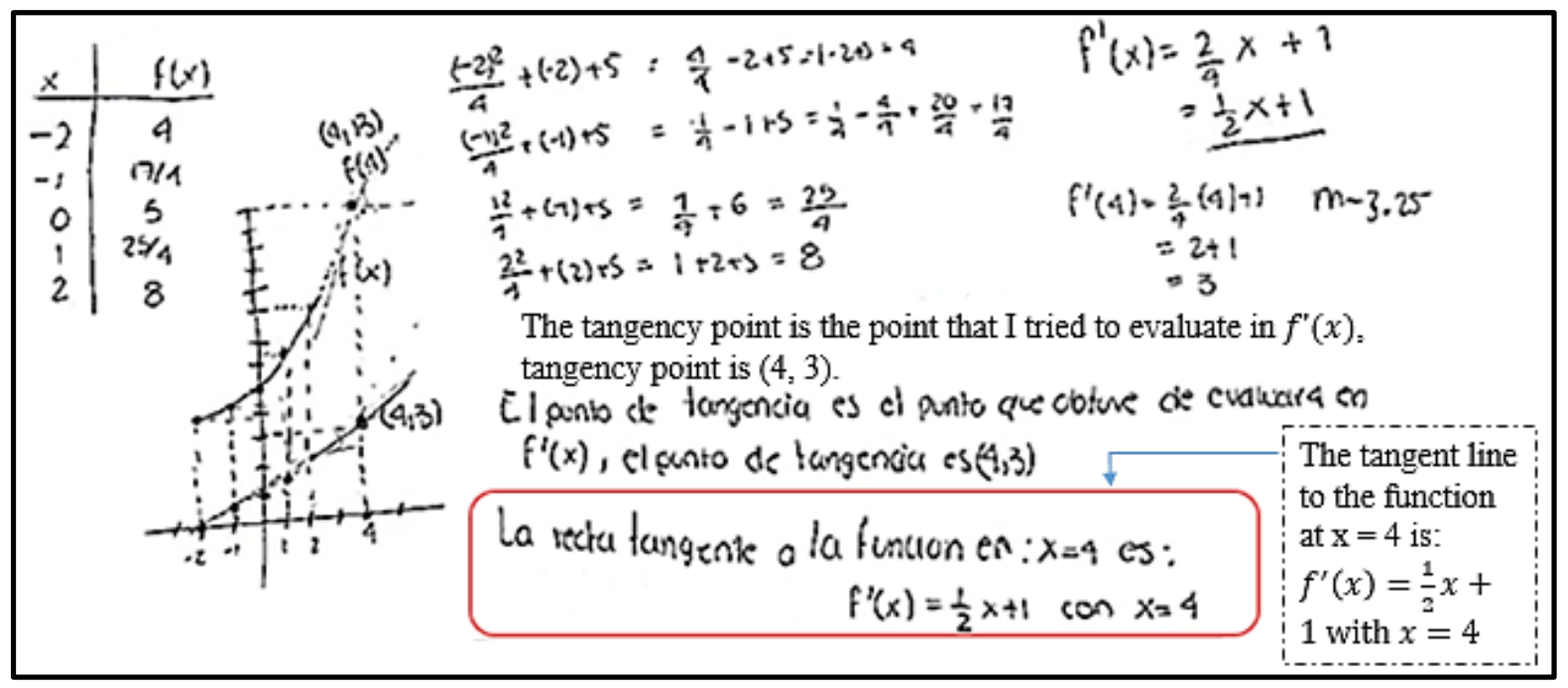

Figure 17. Evidence of disconnection in the procedure done by P1

We maintain that these types of difficulties are caused by not considering the slope of the tangent line in the meaning given for the derivative ( $\mathrm{C} 1$ in Table 2). That is if a subject has the wrong meaning about a mathematical concept when using it in problem-solving it can lead to incorrect answers. The following interview excerpt shows the influence of the meanings that the teacher transmits to his students.

I: What does the derivative mean?

P1: For me the derivative, I have a definition learned from high school. A teacher had told me that the line is tangent to a function and he even pointed out to us with a drawing that we had a quadratic function, for example, it was $f(x)=x^{2}$ and he said that the derivative was $2 x$, he plotted a straight line and it told us that this point where the two of them [the graph of $f^{\prime}$ with the graph of $f$ ] intersected was the derivative. I kept that idea. Here in the mathematics faculty, the teacher also explained a little more to us, but he already gave us a form, told us how these derivatives were obtained and, from there, we already mechanically began to work the derivation rules, how you could view as a limit.

I: How could you see it as a limit? 
P1: The limit of a function plus an increment minus the limit of the original function between the increment.

I: Could you represent her?

P1: Yes, well... that was another way of looking at the derivative.

In the interview excerpt, it was observed that P1 retains the meanings provided by his teacher from the high school level. Therefore, the teacher's mathematical connections of meaning directly influenced those established by $\mathrm{P} 1$, but in this case it is a disconnect since $\mathrm{P} 1$ provided an incomplete meaning: "the derivative is the tangent line to a function" without emphasizing the slope of the line. For his part P3 presented difficulties in achieving this due to the inappropriate use of the point-slope formula $\left[y+y_{1}=m\left(x-x_{1}\right)\right]$, thus arriving at an incorrect linear equation. Likewise, considered the tangent line of the function to be the expression $f^{\prime}(x)=\frac{x}{2}+1$ without emphasizing the slope of the tangent line at the given point. This case suggests that the disconnection of P1 concerning the meaning of the derivative is promoted by the meaning given by their teacher in high school and college, that is, the mathematical connections made by the teacher when addressing a mathematical topic can be reproduced by students such which as they were communicated. With this event, we agree with Byerley and Thompson (2017) when they mentioned that "students return to high schools to teach ideas they understood poorly as school students, rarely revisited in college, and for which they still have poorly-formed meanings" ( $p$ $.191)$.

Just as there were disconnections in the resolution of task 3 by $\mathrm{P} 1$, due to having an inconsistent or incomplete meaning of the derivative, some similar cases also occurred in the study by Sánchez-Matamoros et al. (2008). These authors reported that students did not connect a process associated with the notion of a derivative (rate of change, limit, function) given in one context, with the same process that appears in another context. Also, they concluded that the understanding of the derived concept will be promoted when meanings of rate of change, limit, and function are constructed and connected in different contexts. Furthermore, we agreed with Pambudi et al. (2018) given that, we find that success in problem-solving depends on the mathematical connections that a subject makes. In the case of P1, the result of task 3 was not successful, due to a disconnection or a mathematically inconsistent procedure.

Sánchez-Matamoros et al. (2008) argue that different representations influence the construction of meanings of a subject since they can be considered separately and applied algorithmically without any relationship. The results of this investigation coincide with the statements made by Sánchez-Matamoros et al. (2008), regarding the lack of connections between modes of representation. However, we point out that the algorithmic processes of the students could be caused by their teacher. For example, during the P1 interview, he said: "The teacher also explained a little more to us, but he already gave us a form, told us how these derivatives were obtained and, from there, we mechanically started to work the derivation rules, how could it be seen as a limit".

In summary, this study analyzed the mathematical connections made by five PSMTs when they solved tasks related to the derivative (see Table 6).

Table 6. Frequency of the mathematical connections established by the PSMTs on the derivative

\begin{tabular}{|c|c|c|c|c|c|c|c|c|c|}
\hline \multirow{2}{*}{ Participant } & \multirow{2}{*}{ Task } & \multicolumn{7}{|c|}{ Mathematical connections } & \multirow[b]{2}{*}{ frequency } \\
\hline & & $\mathbf{P}$ & P-W & I & DR & $\mathbf{F}$ & $\mathbf{M}$ & $\mathbf{R}$ & \\
\hline \multirow{3}{*}{1} & 1 & 1 & 0 & 0 & 0 & 1 & 1 & 0 & 3 \\
\hline & 2 & 4 & 2 & 0 & 2 & 0 & 0 & 0 & 8 \\
\hline & 3 & 4 & 2 & 3 & 2 & 0 & 0 & 0 & 11 \\
\hline \multirow{3}{*}{2} & 1 & 1 & 1 & 0 & 4 & 0 & 2 & 0 & 8 \\
\hline & 2 & 1 & 0 & 0 & 0 & 0 & 1 & 0 & 2 \\
\hline & 3 & 0 & 1 & 3 & 3 & 0 & 0 & 0 & 7 \\
\hline \multirow{3}{*}{3} & 1 & 0 & 3 & 0 & 3 & 0 & 3 & 0 & 9 \\
\hline & 2 & 4 & 0 & 0 & 2 & 0 & 1 & 0 & 7 \\
\hline & 3 & 3 & 4 & 3 & 4 & 0 & 0 & 0 & 14 \\
\hline \multirow{3}{*}{4} & 1 & 4 & 3 & 0 & 4 & 0 & 2 & 0 & 13 \\
\hline & 2 & 3 & 0 & 0 & 3 & 0 & 1 & 0 & 7 \\
\hline & 3 & 4 & 3 & 3 & 3 & 0 & 0 & 0 & 13 \\
\hline \multirow{3}{*}{5} & 1 & 2 & 1 & 0 & 4 & 1 & 3 & 0 & 11 \\
\hline & 2 & 6 & 1 & 0 & 5 & 0 & 1 & 0 & 13 \\
\hline & 3 & 6 & 5 & 3 & 3 & 0 & 0 & 0 & 17 \\
\hline Frequency & & 43 & 26 & 15 & 42 & 2 & 15 & 0 & \\
\hline
\end{tabular}




\section{Discussion}

According to the results, mathematical connections of procedural type $(n=43)$ were more frequently evidenced, followed by the mathematical connections of different representations $(n=42)$ and part-whole $(n=$ 26). Those of implication and meaning were presented in equal numbers. However, the connections of different representations and meanings are those that report the previous research that students and teachers do little and therefore, lead them to present difficulties in solving problems (Berry y Nyman, 2006; Hashemi et al., 2014; Moru, 2020; Pino- Fan et al., 2015; 2018; Pino-Fan et al., 2017; Sari et al., 2018; Ubuz, 2007). The mathematical connections of meanings of the derivative (slope of the tangent line to a curve at a point and limit of the incremental quotient) were the most evident, and connections between multiple representations of the derivative also emerged in the written productions of the participants, which in the study by Sari et al. (2018) they are presented as difficult to do.

Also, in the mathematical connections of meaning the part-whole connection was inferred, since only two meanings that belong to a global meaning of the derivative reported in the study of Pino-Fan, Godino and Font (2011) and Pino-Fan (2013). In this sense, it follows that the conformation of a meaning depends on other wellconnected meanings. The part-whole mathematical connections are evidenced in interview excerpts associated with the participants' mathematical connection of meaning (the limit of the incremental quotient and slope of the tangent line), since the derivative has a global epistemic meaning (Pino-Fan et al., 2011, p.174), as shown in Figure 18. The global meaning is made up of nine systems of practices each associated with an epistemic configuration (EC) constituting nine partial meanings of the notion of derivative (EC1, EC2, EC3,..., EC9) (Pino-Fan, 2013), which maintain relationships with each other. In terms of the study of Pino-Fan (2013), the partial meanings are connected and make other meanings emerge, that is, they generate a new system of practices.

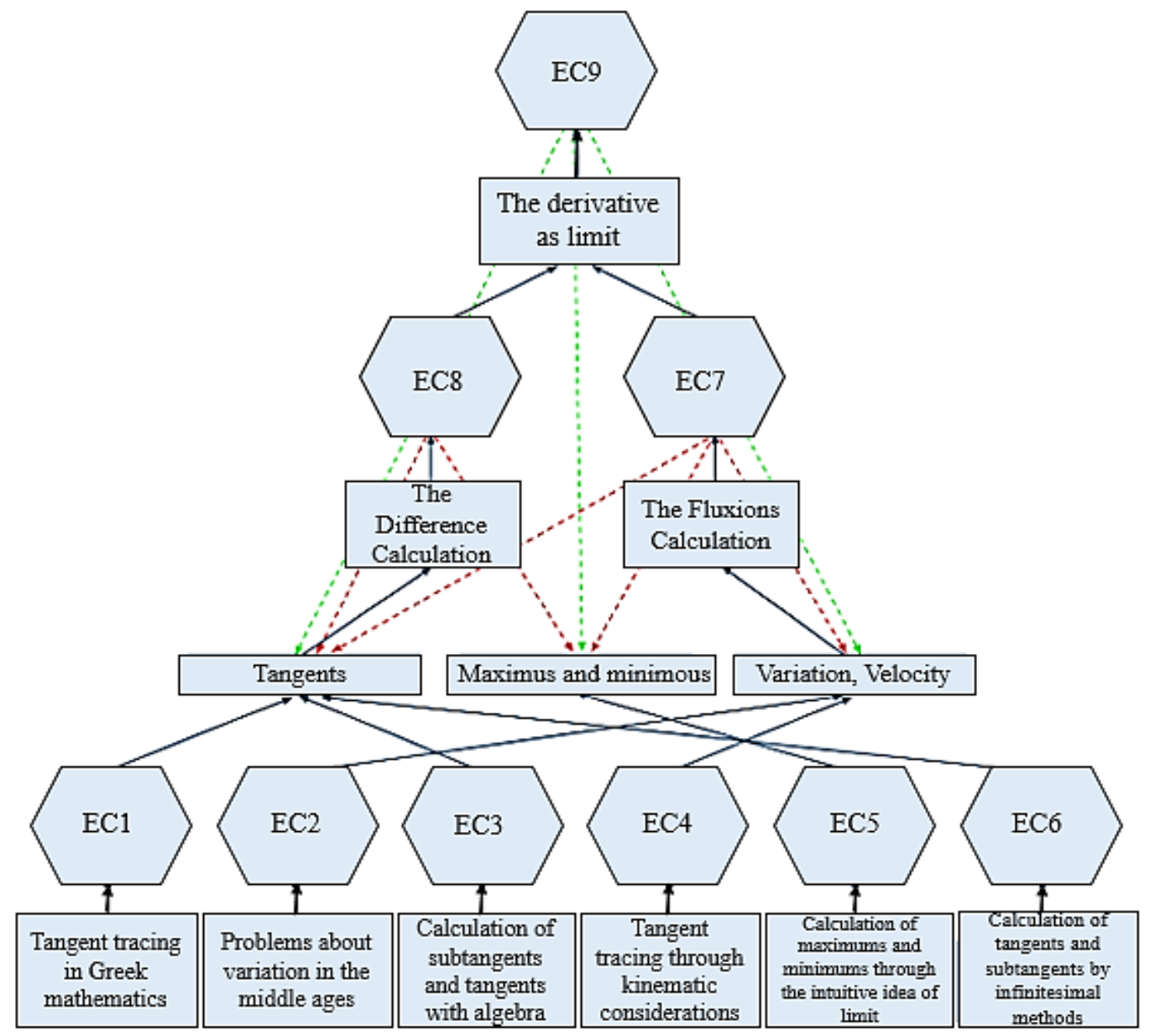

Figure 18. Global epistemic meaning of the derivative (Pino-Fan et al., 2011)

In this sense, Pino-Fan et al. (2011) argue that there are relationships between the different epistemic configurations identified in Figure 18, which:

They could continue to expand, for example, the EC7 configuration that has linked the meaning of the derivative as fluxion, together with some ideas from the EC8 and EC9 configurations, giving rise to a 
new system of practices from which a new branch of mathematics: "The calculation of variations" (p. 173).

The part-whole mathematical connection was evidenced in the global epistemic meaning of the derivative as an inclusion relationship. Also, the analysis of the meaning connections presented in Figure 17 is made specific and especially detailed, which are important for students and teachers to attend so that the difficulties reported in the literature due to the disconnection of meanings are not further promoted partial of the derivative (Pino-Fan $e t$ al., 2015; 2018). In this sense, the EC2 and EC4 configurations are grouped and give rise to a new, more general system of practices with their respective configuration called "variation, velocity" (Pino-Fan, 2013). See Figure 19 where the mathematical connection of meaning (MCM) is evidenced.

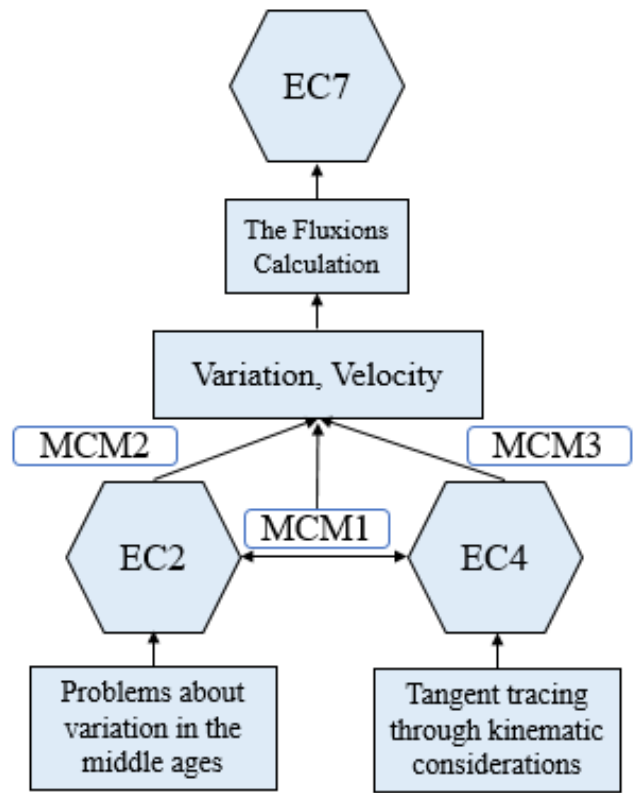

Figure 19. Mathematical connections of meaning and part-whole evidenced in the global epistemic meaning of the derivative (Adopted from Pino-Fan et al. (2011)

Likewise, Figure 19 shows the mathematical connection between meanings where the EC2 and EC4 configurations are related with the configuration underlying the system of practice: variation, velocity and give rise to a new system of practice/partial meaning with its associated configuration: The Fluxions Calculation (EC7) (Pino-Fan et al., 2011). In relation with the mathematical connection of part-whole type, emphasis is placed on the inclusion relation specified in Figure 19, where part 1: EC2 and part 2: EC4, make up the whole: variation, velocity. In the same way, the meaning "The Difference Calculation" (whole) associated with the system of practice "tangent" is conformed with its parts EC1 (part 1), EC3 (part 2) and EC6 (part 3).

We consider it relevant that P5 gave a meaning of the derivative as use when he mentioned "in differential Geometry, we use the derivatives of a function to determine the trihedron of a curve". Implicitly involved is the meaning of the derivative as the slope of the tangent line to a curve at a point. Going deeper into the part-whole mathematical connection, our results coincide with those reported by García-García and Dolores-Flores (2019) when they stated that students recognize parts of a graph $y=f(x)$, that is, analyze the graph at the extremes, as well as the behavior of the graph of the function at certain intervals. In this work, it was also recognized that PSMTs identified intervals (indicating sectors or parts of the graph sketch) where productivity increases or decreases. It is valid to mention that the mathematical connection of reversibility was not evident in the responses of the PSMTs. It could be said that these mathematical connections did not emerge due to the type of tasks proposed. For example, in the work of García-García and Dolores-Flores (2019), the mathematical connection of reversibility emerged since the students were proposed a task where they had to sketch the graph of the derived function, given the graph of the function $f(x)$ and viceversa, as well as sketch the graph of its antiderivative function given the graph of the derived function $f^{\prime}(x)$.

\section{Conclusion}

The results obtained from the thematic analysis allowed recognizing mathematical connections when the PSMT solved the proposed tasks. These results show that the difficulties of the PSMT, for example, are possibly caused by the meaning they have on the derivative, product of the education received and that, if not addressed with special attention, they can be reproduced in their future practice as teachers in service. In the same way, they show difficulties in achieving the procedural mathematical connection when they do not consistently use 
meaning when solving an application problem. Generally, in the answer to task 1, the use of meanings of the derivative was observed in most of the answers, associating them with different representations. In the answers to task 2, it was shown that PSMTs prefer to use the meaning of the derivative as the slope of the tangent line to the curve at one point. In the context of the application problem (task 3), it was shown that PSMTs adequately solved the task, using different representations of the derivative and the function that models productivity.

Finally, we recognize that this research is a case study, so the results are not generalizable; however, evidence is given about the situation surrounding PSMTs. That is, the mathematical connections that they manage to establish by solving mathematical tasks can be taught in their future practice, stimulating students to develop or not the ability to make mathematical connections. In future studies we suggest studying the connections with a larger population to generalize the results. Also, we consider it important to explore the quality of the mathematical connections that students make, PSMTs and in-service teachers when solving mathematical tasks, and how these connections influence the understanding of mathematical concepts. It is suggested to study mathematical connections considering integrations with other theoretical frameworks that consider the connections to be fundamental in order to make more detailed analyzes, for example, a future work would be directed towards the mathematical connections between the different meanings and representations of the derivative and through from these connections achieve mathematical understanding of the same concept.

\section{Acknowledgment}

To CONACYT for the financing provided to PhD student Camilo Andrés Rodríguez-Nieto in his doctoral studies at the Autonomous University of Guerrero, Mexico. Also, we are grateful to the PSMTs who participated in this research.

\section{Disclosure statement}

No potential conflict of interest was reported by the authors.

\section{References}

Adams, W. C. (2015). Conducting semi-structured interviews. In K. E. Newcomer, H. P. Hatry, \& J. S. Wholey (Eds.), Handbook of practical program evaluation (pp. 492-505). (Fourth ed.). New Jersey: Wiley.

Antonio, R., Escudero, D. I., \& Flores, E. (2019). Una introducción al concepto de derivada en estudiantes de bachillerato a través del análisis de situaciones de variación [An introduction to the concept of derivative in high school students]. Revista Educación matemática, 31(1), 258-280. https://doi.org/10.24844/EM3101.10

Autonomous University of Guerrero [UAGro]. (2009). Plan de Estudios de la licenciatura en Matemáticas. México: Autor.

Berry, J. y Nyman, M. (2003). Promoting students' graphical understanding of the calculus. The Journal of Mathematical Behavior, 22(4), 479-495. https://doi.org/10.1016/j.jmathb.2003.09.006

Borji, V., Font, V., Alamolhodaei, H., \& Sánchez, A. (2018). Application of the Complementarities of Two Theories, APOS and OSA, for the Analysis of the University Students' Understanding on the Graph of the Function and its Derivative. EURASIA Journal of Mathematics, Science and Technology Education, 14(6), 2301-2315. https://doi.org/10.29333/ejmste/89514

Braun, V., \& Clarke, V. (2006). Using thematic analysis in psychology. Qualitative Research in Psychology, 3(2), 77-101. https://doi.org/10.1191/1478088706qp063oa

Businskas, A. M. (2008). Conversations about connections: How secondary mathematics teachers conceptualize and contend with mathematical connections [Unpublished PhD Thesis]. Faculty of Education-Simon Fraser University, Canada.

Byerley, C., \& Thompson, P. W. (2017). Secondary mathematics teachers' meanings for measure, slope, and rate of change. The Journal of Mathematical Behavior, 48, 168-193. https://doi.org/10.1016/j.jmathb.2017.09.003

Carter, N., Bryant-Lukosius, D., DiCenso, A., Blythe, J., \& Neville, A., J. (2014). The use of triangulation in qualitative research. Oncology Nursing Forum, 41, 545-547. https://doi:10.1188/14.ONF.545-547

Cohen, L., Manion, L., \& Morrison, K. (2018). Research methods in education. London and New York: Routledge.

Departament d'Ensenyament. (2017). Competències bàsiques de l'àmbit matemàtic. Recuperado de: http://ensenyament.gencat.cat/web/.content/home/departament/publicacions/colleccions/competenc iesbasiques/eso/eso-matematic.pdf.

Dirección General de Bachillerado [DGB]. (2018). Cálculo diferencial. Recuperado el 06 de diciembre de 2019 https://www.dgb.sep.gob.mx/informacion-academica/programas-de-estudio/CFP/5to-Semestre/CalculoDiferencial.pdf 
Dolores-Flores, C., \& García-García, J. (2017). Conexiones Intramatemáticas y Extramatemáticas que se producen al Resolver Problemas de cálculo en Contexto: Un Estudio de Casos en el Nivel Superior. Bolema - Mathematics Education Bulletin, 31(57), 158-180. https://doi.org/10.1590/1980-4415v31n57a08

Dolores-Flores, C., Rivera-López, M. I., \& García-García, J. (2019). Exploring mathematical connections of preuniversity students through tasks involving rates of change. International Journal of Mathematical Education in Science and Technology, 50(3), 369-389. https://doi.org/10.1080/0020739X.2018.1507050

Duval, R. (2006). A cognitive analysis of problems of comprehension in a learning of mathematics. Educational Studies in Mathematics, 61, 103-131. https://doi.org/10.1007/s10649-006-0400-z

Eli, J. A., Mohr-Schroeder, M. J., \& Lee, C. W. (2013). Mathematical Connections and Their Relationship to Mathematics Knowledge for Teaching Geometry. School Science and Mathematics, 113(3), 120-134. https://doi.org/10.1111/ssm.12009

Evitts, T. (2004). Investigating the mathematical connections that preservice teachers use and develop while solving problems from reform curricula. [Unpublished dissertation], Pennsylvania State University College of Education. United States of America.

Fuentealba, C., Badillo, E., \& Sánchez-Matamoros, G. (2018). Puntos de no-derivabilidad de una función y su importancia en la comprensión del concepto de derivada [The non-derivability points of a function and their importance in the understanding of the derivative concept]. Educação e Pesquisa, 44, 1-20. https://doi.org/10.1590/s1678-4634201844181974

Fuentealba, C., Badillo, E., \& Sánchez-Matamoros, G. (2019). Identificación y caracterización de los subniveles de desarrollo del esquema de derivada. Enseñanza de las Ciencias, 37(2), 63-84. https://doi.org/10.5565/rev/ensciencias.2518

Fuentealba, C., Badillo, E., Sánchez-Matamoros, G., \& Cárcamo, A. (2018). The understanding of the derivative concept in higher education. EURASIA Journal of Mathematics, Science and Technology Education, 15(2), 1-15. https://doi.org/10.29333/ejmste/100640

Gagatsis, A., \& Shiakalli, M. (2004). Ability to translate from one representation of the concept of function to another and mathematical problem solving. Educational Psychology, 24(5), 645-657. https://doi.org/10.1080/0144341042000262953

García-García, J. (2018). Conexiones matemáticas y concepciones alternativas asociadas a la derivada y a la integral en estudiantes del preuniversitario [Mathematical connections and alternative conceptions associated with the derivative and the integral in pre-university students]. (Unpublished doctoral dissertation). Autonomous University of Guerrero, Mexico.

García-García, J. G. (2019). Escenarios de exploración de conexiones matemáticas [mathematical connection exploration scenarios]. Números: Revista de Didáctica de las Matemáticas, 4 (100), 129-133.

García-García, J., \& Dolores-Flores, F. (2020). Exploring pre-university students' mathematical connections when solving Calculus application problems. International Journal of Mathematical Education in Science and Technology, https://doi.org/10.1080/0020739X.2020.1729429

García-García, J., \& Dolores-Flores, C. (2018). Intra-mathematical connections made by high school students in performing Calculus tasks. International Journal of Mathematical Education in Science and Technology, 49(2), 227-252. https://doi.org/10.1080/0020739X.2017.1355994

García-García, J., \& Dolores-Flores, C. (2019). Pre-university students' mathematical connections when sketching the graph of derivative and antiderivative functions. Mathematics Education Research Journal, https://doi.org/10.1007/s13394-019-00286-X

Hashemi, N., Abu, M. S., Kashefi, H., \& Rahimi, K. (2014). Undergraduate students' difficulties in conceptual understanding of derivation. Procedia-Social and Behavioral Sciences, 143, 358-366.

Herbert, S., \& Pierce, R. (2011). What is rate? Does context or representation matter?. Mathematics education research journal, 23(4), 455-477. https://doi.org/10.1007/s13394-011-0026-Z

Kenedi, A. K., Helsa, Y., Ariani, Y., Zainil, M., \& Hendri, S. (2019). Mathematical connection of elementary school students to solve mathematical problems. Journal on Mathematics Education, 10(1), 69-80.

Kula-Ünver, S. (2020). How do pre-service mathematics teachers respond to students' unexpected questions related to the second derivative?. Journal of Pedagogical Research, 4(3), 359-374.

Mwakapenda, W. (2008). Understanding connections in the school mathematics curriculum. South African Journal of Education, 28(2), 189-202.

Mhlolo, M. K. (2012). Mathematical connections of a higher cognitive level: A tool we may use to identify these in practice. African Journal of Research in Mathematics, Science and Technology Education, 16(2), 176191. https://doi.org/10.1080/10288457.2012.10740738

Ministerio de Educación Nacional (Ministry of National Education) [MEN]. (2006). Estándares básicos de competencias en lenguaje, Matemáticas, ciencia y ciudadanas. Bogotá, Colombia: MEN.

Ministry of Education [MOE] (2006a). Mathematics syllabuses - Primary. Singapore: Author.

Ministry of Education [MOE] (2006b). Mathematics syllabuses - Lower secondary. Singapore: Author. 
Moru, E. K. (2020). An APOS analysis of university students' understanding of derivatives: A Lesotho case Study. African Journal of Research in Mathematics, Science and Technology Education, 24(2), 279-292. https://doi.org/10.1080/18117295.2020.1821500

National Council of Teachers of Mathematics (NCTM). (2000). Principles and standards for school mathematics. Reston: National Council of Teachers of Mathematics.

Nowell, L. S., Norris, J. M., White, D. E., \& Moules, N. J. (2017). Thematic analysis: Striving to meet the trustworthiness criteria. International Journal of Qualitative Methods, 16(1), 1-13. https://doi.org/10.1177/1609406917733847

Özgen, K. (2013). Self-efficacy beliefs in mathematical literacy and connections between mathematics and real world: The case of high school students. Journal of International Education Research, 9(4), 305-316. https://doi.org/10.19030/jier.v9i4.8082

Pambudi, D. S., Budayasa, I. K., \& Lukito, A. (2018). Mathematical connection profile of junior high school students in solving mathematical problems based on gender difference. International Journal of Scientific Research and Management, 6(08), 73-78. https://doi.org/10.18535/ijsrm/v6i8.m01

Pino-Fan, L., Godino, J., \& Font, V. (2011). Faceta epistémica del conocimiento didáctico-matemático sobre la derivada [Epistemic facet of the didactic-mathematics knowledge about the derivative]. Educação Matemática Pesquisa, 13(1), 141-178.

Pino-Fan, L. (2013). Evaluación de la faceta epistémica del conocimiento didáctico-matemático de futuros profesores de bachillerato sobre la derivada [Evaluation of the epistemic facet of the didactic-mathematical knowledge of future high school teachers about the derivative] (Unpublished doctoral dissertation). Universidad de Granada.

Pino-Fan, L., Godino, J. D., \& Font, V. (2015). Una propuesta para el análisis de las prácticas matemáticas de futuros profesores sobre derivadas [A Proposal for the analysis of Prospective teachers' mathematical practices on Derivatives]. Bolema - Mathematics Education Bulletin, 29(51), 60-89. https://doi.org/10.1590/1980-4415v29n51a04

Pino-Fan, L., Godino, J, D., \& Font, V. (2018). Assessing key epistemic features of didactic mathematical knowledge of prospective teachers: the case of the derivative. Journal of Mathematics Teacher Education, https://doi:10.1007/s10857-016-9349-8

Pino-Fan, L., Guzmán, I., Font, V., \& Duval, R. (2017). Analysis of the underlying cognitive activity in the resolution of a task on derivability of the absolute-value function: Two theoretical perspectives. PNA, $11(2)$, $97-124$.

Rees, P. K., Sparks, F. W., \& Sparks, C. (1991). Álgebra. México: McGraw Hill.

Rodríguez-Nieto, C. A. (2020). Explorando las conexiones entre sistemas de medidas usados en prácticas cotidianas en el municipio de Baranoa [Exploring the connections between measurement systems used in daily practices in the municipality of Baranoa]. IE Revista de Investigación Educativa de la REDIECH, 11, e857. https://doi.org/10.33010/ie_rie_rediech.v11i0.857

Rodríguez-Nieto, C., Rodríguez-Vásquez, F. M., \& Font, V. (2020). A new view about connections. The mathematical connections established by a teacher when teaching the derivative. International Journal of Mathematical Education in Science and Technology. https://doi.org/10.1080/0020739X.2020.1799254

Rodríguez-Nieto, C., Font, V., Borji, V., \& Rodríguez-Vásquez, F. M. (2021). Mathematical connections from a networking of theories between extended theory of mathematical connections and onto-semiotic approach. International Journal of Mathematical Education in Science and Technology. https://doi.org/10.1080/0020739X.2021.1875071

São Paulo [state]. (2012). Currículo do Estado de São Paulo: matemática e suas tecnologias. Secretaria da Educação, São Paulo, Brasil.

Sari, P., Hadiyan, A., \& Antari, D. (2018). Exploring derivatives by means of GeoGebra. International Journal on Emerging Mathematics Education, 2(1), 65-78. https://doi.org/10.12928/ijeme.v2i1.8670

Sánchez-Matamoros, G., García, M., \& Llinares, S. (2008). La comprensión de la derivada como objeto de investigación en didáctica de la matemática [The understanding of derivate as the object of investigation in mathematics education]. Revista latinoamericana de investigación en matemática educativa, 11(2), 267-296.

Sánchez-Matamoros, G., Fernández, C., \& Llinares, S. (2015). Developing pre-service teachers' noticing of students' understanding of the derivative concept. International journal of science and mathematics education, 13(6), 1305-1329. https://doi.org/10.1007/s10763-014-9544-y

Steward, J. (1999). Cálculo. Conceptos y contextos [Calculus. Concepts and contexts]. Thomson, México.

Ubuz, B. (2007). Interpreting a graph and constructing its derivative graph: stability and change in students' conceptions. International Journal of Mathematical Education in Science and Technology, 38(5), 609-637. https://doi.org/10.1080/00207390701359313

Yavuz-Mumcu, H. (2018). Matematiksel ilişkilendirme becerisinin kuramsal boyutta incelenmesi: türev kavramı örneği. Turkish Journal of Computer and Mathematics Education, 9(2), 211-248. https://doi.org/10.16949/turkbilmat.379891 